\title{
Biatrial maze procedure versus pulmonary vein isolation for atrial fibrillation during mitral valve surgery: New analytical approaches and end points
}

Eugene H. Blackstone, MD, ${ }^{\mathrm{a}, \mathrm{b}}$ Helena L. Chang, MS, ${ }^{\mathrm{c}}$ Jeevanantham Rajeswaran, PhD, ${ }^{\mathrm{b}}$ Michael K. Parides, PhD, ${ }^{\mathrm{c}}$ Hemant Ishwaran, $\mathrm{PhD},{ }^{\mathrm{d}}$ Liang Li, PhD, ${ }^{\mathrm{e}}$ John Ehrlinger, PhD, Annetine C. Gelijns, PhD, ${ }^{\mathrm{c}}$ Alan J. Moskowitz, MD, ${ }^{\mathrm{c}}$ Michael Argenziano, MD, ${ }^{\mathrm{f}}$ Joseph J. DeRose, Jr, MD, ${ }^{g}$ Jean-Phillipe Couderc, PhD, MBA, ${ }^{\mathrm{h}}$ Dan Balda, MD, ${ }^{\mathrm{i}}$ François Dagenais, MD ${ }^{\mathrm{j}}$ Michael J. Mack, MD, ${ }^{\mathrm{k}}$ Gorav Ailawadi, MD, ${ }^{1}$ Peter K. Smith, MD, ${ }^{\mathrm{m}}$ Michael A. Acker, MD, ${ }^{\mathrm{n}}$ Patrick T. O' Gara, MD, ${ }^{\circ}$ and A. Marc Gillinov, MD, ${ }^{a}$ for the Cardiothoracic Surgical Trials Network Investigators

\section{ABSTRACT}

Objective: To use novel statistical methods for analyzing the effect of lesion set on (long-standing) persistent atrial fibrillation (AF) in the Cardiothoracic Surgical Trials Network trial of surgical ablation during mitral valve surgery (MVS).

Methods: Two hundred sixty such patients were randomized to MVS + surgical ablation or MVS alone. Ablation was randomized between pulmonary vein isolation and biatrial maze. During 12 months postsurgery, 228 patients $(88 \%)$ submitted 7949 transtelephonic monitoring (TTM) recordings, analyzed for AF, atrial flutter (AFL), or atrial tachycardia (AT). As previously reported, more ablation than MVS-alone patients were free of AF or AF/AFL at 6 and 12 months $(63 \%$ vs $29 \% ; P<.001)$ by 72 -hour Holter monitoring, without evident difference between lesion sets (for which the trial was underpowered).

Results: Estimated freedom from AF/AFL/AT on any transmission trended higher after biatrial maze than pulmonary vein isolation (odds ratio, 2.31; 95\% confidence interval, $0.95-5.65 ; P=.07) 3$ to 12 months postsurgery; estimated $\mathrm{AF} /$ AFL/AT load (ie, proportion of TTM strips recording AF/AFL/AT) was similar (odds ratio, $0.90 ; 95 \%$ confidence interval, $0.57-1.43 ; P=.6$ ). Within 12 months, estimated prevalence of AF/AFL/AT by TTM was $58 \%$ after MVS alone, and $36 \%$ versus $23 \%$ after pulmonary vein isolation versus biatrial maze $(P<.02)$.

Conclusions: Statistical modeling using TTM recordings after MVS in patients with (long-standing) persistent AF suggests that a biatrial maze is associated with lower AF/AFL/AT prevalence, but not a lower load, compared with pulmonary vein isolation. The discrepancy between AF/AFL/AT prevalence assessed at

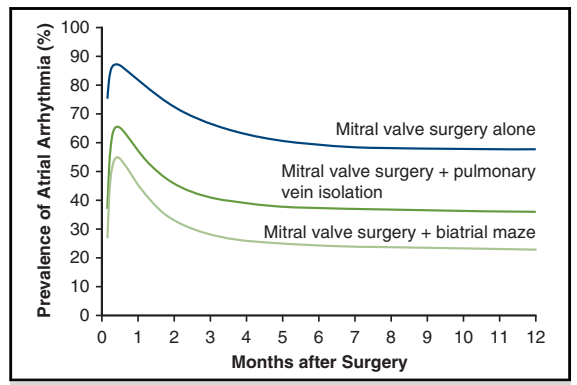

Estimated prevalence of atrial arrhythmia after mitral valve surgery with or without atrial ablation.

Central Message
A biatrial maze may be associated with lower prevalence of
atrial arrhythmias than pulmonary vein isolation for atrial
fibrillation. These findings and analytic approach require
confirmation.

Perspective

Thirty percent to $50 \%$ of patients undergoing mitral valve surgery have atrial fibrillation. Ablation increases likelihood of return to normal sinus rhythm; however, lesion set choice is controversial. A novel analysis of weekly transtelephonic recordings suggests biatrial maze may be associated with fewer atrial arrhythmias than pulmonary vein isolation. This inference and analytic approach require confirmation.

See Editorial Commentaries pages 244 and 246

See Editorial page 231.

From the ${ }^{\text {aDDepartment }}$ of Thoracic and Cardiovascular Surgery, Cleveland Clinic, Cleveland, Ohio; 'bepartment of Quantitative Health Sciences, Cleveland Clinic, Cleveland, Ohio; ${ }^{\mathrm{c}}$ Department of Population Health Science and Policy, Icahn School of Medicine at Mount Sinai, New York, NY; ${ }^{\mathrm{d}}$ Department of Public Health Sciences, Division of Biostatistics, University of Miami, Miami, Fla; ${ }^{\mathrm{e}}$ Department of Biostatistics, The University of Texas MD Anderson Cancer Center, Houston, Tex; ${ }^{\mathrm{f}}$ Division of Cardiothoracic Surgery, Department of Surgery, College of Physicians and Surgeons, Columbia University, New York, NY; ${ }^{\mathrm{g}}$ Department of Cardiovascular and Thoracic

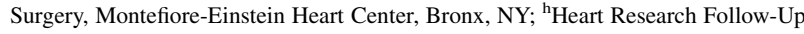
Program, Cardiology Department, University of Rochester Medical Center, Rochester, NY; ${ }^{i}$ Medicomp, Inc, Melbourne, Fla; ${ }^{j}$ Department of Cardiac Surgery, Institut Universitaire de Cardiologie de Québec, Hôpital Laval, Québec City, Québec, Canada; ${ }^{k}$ Department of Cardiothoracic Surgery, Baylor Research Institute, Baylor Health Care System, Plano, Tex; 'Division of Thoracic and Cardiovascular Surgery, University of Virginia School of Medicine, Charlottesville, Va; ${ }^{\mathrm{m}}$ Division of Cardiovascular and Thoracic Surgery, Department of Surgery, Duke University Medical Center, Durham, NC; ${ }^{\text {n}}$ Department of Surgery, Division of Cardiovascular Surgery, University of Pennsylvania School of Medicine, Philadelphia, $\mathrm{Pa}$; and ${ }^{\circ} \mathrm{Cardiovascu}-$ lar Medicine Division, Brigham and Women's Hospital, Boston, Mass.
Supported by grant No. R01 HL103552 and by a cooperative agreement (No. U01 HL088942) with the National Heart, Lung, and Blood Institute, including funding by the National Institute of Neurological Disorders and Stroke and the Canadian Institutes of Health Research.

Dr Parides is currently affiliated with the Department of Cardiovascular and Thoracic Surgery, Montefiore-Einstein Heart Center, Bronx, NY.

A complete list of investigators in the Cardiothoracic Surgical Trials Network is provided in Appendix E1.

Read at the 97th Annual Meeting of The American Association for Thoracic Surgery, Boston, Massachusetts, April 29-May 3, 2017.

Received for publication May 1, 2017; revisions received June 7, 2018; accepted for publication June 27, 2018.

Address for reprints: Eugene H. Blackstone, MD, Department of Thoracic and Cardiovascular Surgery, Cleveland Clinic, 9500 Euclid Ave, Desk JJ-40, Cleveland, OH 44195 (E-mail: blackse@ @cf.org).

$0022-5223 / \$ 36.00$

Copyright $(\underset{2}{ } 2018$ by The American Association for Thoracic Surgery

https://doi.org/10.1016/j.jtcvs.2018.06.093 


$$
\begin{aligned}
& \text { Abbreviations and Acronyms } \\
& \text { AF }=\text { atrial fibrillation } \\
& \text { AFL }=\text { atrial flutter } \\
& \text { AT }=\text { atrial tachycardia } \\
& \text { CTSN }=\text { Cardiothoracic Surgical Trials Network } \\
& \text { MVS }=\text { mitral valve surgery } \\
& \text { NIH }=\text { National Institutes of Health } \\
& \text { PVI }=\text { pulmonary vein isolation } \\
& \text { TTM }=\text { transtelephonic monitoring }
\end{aligned}
$$

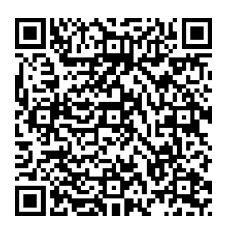
the webcast thumbnail.

2 time points by Holter monitoring versus weekly TTM suggests the need for a confirmatory trial, reassessment of definitions for failure after ablation, and validation of statistical methods for assessing atrial rhythms longitudinally. (J Thorac Cardiovasc Surg 2019;157:234-43)

The Cardiothoracic Surgical Trials Network (CTSN), sponsored by the National Institutes of Health and Canadian Institutes of Health (ClinicalTrials.gov identifier: NCT00903370), randomized 260 patients $1: 1$ with persistent or long-standing persistent atrial fibrillation (AF) associated with mitral valve disease to either mitral valve surgery (MVS) with left atrial appendage closure or MVS with an ablation procedure for AF. ${ }^{1}$ At both 6 and 12 months, $63 \%$ of patients in the ablation arm were free of $\mathrm{AF}$ as assessed by 72-hour continuous Holter monitoring versus $29 \%$ of patients in the nonablation arm. The ablation arm was further randomized into 2 different ablative lesion sets: pulmonary-vein isolation alone (PVI) or biatrial maze (Appendix E2 and Figure E1), which had similar apparent efficacy for the primary 1-year trial end point $(61 \%$ vs $66 \%$ free of AF, respectively). ${ }^{2}$ However, the trial was not powered to detect a difference in $\mathrm{AF}$ prevalence between ablative lesion sets when assessed with Holter monitoring.

A secondary objective of the trial was to compare 2 techniques for postablation heart rhythm monitoring to guide follow-up strategies for future studies of rhythm control in AF patients: 72-hour Holter monitoring at 6 and 12 months and weekly and symptom-related transtelephonic monitoring (TTM) recordings. ${ }^{1}$ The present study focuses on these TTM recordings and the application of 2 statistical models to estimate occurrence of AF, atrial flutter (AFL), and atrial tachycardia (AT). Because TTM data are composed of periodically sampled, short binary rhythm snapshots, such data present a statistical challenge. Therefore, The National Heart, Lung, and Blood Institute funded a multicenter ancillary R01 (HI, JE, JR, MKP; Co-PIs EHB and LL) with the aim of developing alternative methods to analyze these types of longitudinal data. We hypothesized that more frequent rhythm assessment by TTM would increase power to detect outcome differences between the 2 ablative lesion sets. Objectives of this study were to use these new statistical methods to identify the temporal pattern of AF/AFL/AT for each of the 3 trial arms, compare these patterns, and estimate with increased precision the potential magnitude of differences in indices of AF/AFL/AT between PVI and biatrial lesion sets.

\section{PATIENTS AND METHODS Trial Design}

Between 2010 and 2013, 260 patients with (long-standing) persistent AF scheduled for MVS at 1 of 20 CTSN centers were randomized 1:1 to MVS and concomitant left atrial appendage closure alone (MVS alone) $(\mathrm{n}=127)$ or MVS and surgical ablation with left atrial appendage closure (MVS + ablation) $(\mathrm{n}=133)$, stratified by site using a random permuted block design, with block size of 4 or 8 chosen at random. ${ }^{1}$ Patients randomized to ablation were further randomized in this same fashion $1: 1$ to PVI $(n=67)$ or biatrial maze $(n=66)$.

CTSN investigators designed the trial, which was approved by institutional review boards at each participating center, and all patients provided written informed consent. A data coordinating center, an independent events adjudication committee, and a data and safety monitoring board appointed by the NIH oversaw trial progress. Because devices were not approved for AF treatment, the trial was conducted under an investigational device exemption.

\section{Patients}

Patients were generally elderly, with a high prevalence of diabetes; most were taking anticoagulants; and concomitant coronary artery bypass grafting was performed in $20 \%$, a tricuspid valve procedure in $38 \%$, and aortic valve replacement in $13 \%$ (Table E1).

\section{End Points}

The end point for this analysis was AF/AFL/AT lasting $\geq 30$ seconds on weekly postdischarge TTM recordings. ${ }^{3}$ During the index hospitalization, patients were given a TTM device (Medicomp, Melbourne, Fla) capable of recording 90-second rhythm strips, and instructed to transmit telephonically to the Medicomp central monitoring facility 1 strip weekly for 12 months. To ensure the monitoring schedule was independent of confounders, patients were instructed to transmit the strip on a specified day and time. In addition, patients with symptoms suggestive of an arrhythmia were instructed to transmit a rhythm strip. TTM recordings were submitted by 228 patients $(88 \%) ; 547$ of 8496 recordings $(6.4 \%)$ were not evaluable because of missing or poor quality transmissions, or indeterminate atrial rhythms (Figure E2). Medicomp, the data coordinating center, and site investigators interacted with patients to encourage compliance. Medicomp analyzed the TTM recordings, blinded to randomization group, to assess atrial rhythm.

Medicomp classified rhythms as 1 or more of AF, AFL, AT, sinus rhythm, junctional rhythm, heart block, atrial pacing, or atrioventricular 
sequential pacing. An electrocardiogram core laboratory overread $20 \%$ of rhythm strips. Of the 7949 recordings evaluated (Figure E3 and Appendix E3), 3668 showed AF, 235 AFL, $290 \mathrm{AF}$ and AFL, and $21 \mathrm{AT} ; 3655$ showed sinus rhythm, 63 junctional rhythm, and 17 heart block. Both scheduled and unscheduled TTMs were included for all analyses.

\section{Analysis End Point Definitions}

Freedom from AF/AFL/AT is defined as no AF/AFL/AT detected on any TTM transmission after a 3-month blanking period. The 3-month blanking period may be called the therapy stabilization period ${ }^{4,5}$ based on the assumption that temporary inflammatory processes following an ablation or surgical procedure may cause AF/AFL/AT independent of the ablation procedure effectiveness.

AF/AFL/AT load is defined as the proportion of each patient's TTM recordings documenting AF/AFL/AT after a 3-month blanking period. ${ }^{6}$

$\mathrm{AF} / \mathrm{AFL} / \mathrm{AT}$ prevalence is defined as the proportion of patients in a group that is in AF/AFL/AT at any given timepoint. ${ }^{6-13}$

\section{Data Analysis}

Two complementary analytical methods were used: a 2-part zeroinflated negative binomial model to estimate freedom from AF/AFL/AT and AF/AFL/AT load, and a temporal decomposition parametric nonlinear mixed-effects model to estimate AF/AFL/AT prevalence. The zero-inflated negative binomial model provided a broad picture of AF/AFL/AT occurrence and load from 3 to 12 months after surgery, whereas the temporal decomposition model added finer details to the overall temporal pattern of prevalence of AF/AFL/AT from surgery to 12 months, incorporating procedure- and time-specific features. Analyses used SAS version 9.4 (SAS Inc, Cary, NC) and R version 3.3.1 (R Foundation for Statistical Computing, Vienna, Austria).

Freedom from AF/AFL/AT and AF/AFL/AT load. After a 3-month blanking period, 6127 TTMs from 191 patients (95 MVS alone, $50 \mathrm{MVS}+\mathrm{PVI}$, and $46 \mathrm{MVS}+$ biatrial maze) were available to assess AF/AFL/AT load. A zero-inflated negative binomial model was used to account for the large frequency of zeros (29\%), meaning no documented AF/AFL/AT on any TTM rhythm strip (freedom from AF/AFL/AT), and the substantial heterogeneity of AF/AFL/AT among the remaining patients. The 2-part modeling of the zero-inflated negative binomial regression provided the effect of randomized assignment on freedom from AF/AFL/AT and the relative frequency of AF/AFL/AT occurrence over time among those who developed it. Logistic regression was used to model the probability of being free of AF/AFL/AT; negative binomial regression was used to model mean number of TTM recordings documenting AF/AFL/AT from 3 through 12 months. In both regression models, randomized assignment was evaluated. The negative binomial model also included a covariate for the $(\log )$ number of TTM strips each patient transmitted to account for variation in number of interpretable TTM transmissions submitted. The regression coefficient of this covariate-an offset-was set to 1.0.

AF/AFL/AT prevalence. A nonlinear logistic mixed-model temporal decomposition model was used to resolve a number of temporal phases (or periods) in the odds domain and estimate the shaping parameters for each (Appendix E4). Each phase was modulated by a function of time and a patient-specific random effect, along with a log-linear model of randomization group. ${ }^{7}$ It was implemented using PROC NLMIXED (in SAS). Prevalence of AF/AFL/AT over time was estimated by averaging individual patient-specific profiles generated by the resulting model.

To illustrate the method, Figure E4 shows 2 temporal components making up the temporal decomposition model for AF/AFL/AT. The first is a peaking phase representing early occurrence of AF/AFL/AT after surgery. The second appears later after surgery and reaches a plateau. Figure E5 shows modeled AF/AFL/AT profiles for each patient. Notice the grouping of profiles near $100 \%$ (continuous AF/AFL/AT) and $0 \%$ (no AF/AFL/AT), with many profiles in between. The ensemble average of these individual profiles reveals a peaking period over the first few months, after which prevalence stabilizes at a constant value (Figure E6).

\section{RESULTS \\ Freedom From AF/AFL/AT}

After a 3-month blanking period, more patients in the ablation group were free from AF/AFL/AT on any TTM recording during months 3 through 12 after surgery than in the MVS-alone group ( $43 \%$ vs $16 \%$, respectively; odds ratio [OR], 4.04; 95\% confidence interval [CI], 1.89-8.64; $P<.001$ ) (Table 1 and Figure 1, A). When compared with MVS alone, patients after either PVI $(34 \%)$ or a biatrial maze $(52 \%)$ were more likely to be free from AF/AFL/AT (PVI vs MVS alone: OR, 2.64; $95 \%$ CI, 1.07-6.51; $P=.04$; biatrial maze vs MVS alone: OR, 6.11; 95\% CI, 2.56-14.61; $P<.001$ ) (Table 1 and Figure 1, $B$ ). Freedom from AF/AFL/AT trended higher among patients randomized to a biatrial maze than those randomized to PVI (OR, 2.31; 95\% CI, 0.95-5.65; $P=.07)$.

\section{AF/AFL/AT Load}

After the 3-month blanking period, the proportion of TTM recordings documenting AF/AFL/AT (ie, AF/AFL/ AT load) was lower in the ablation groups than in the MVS-alone group (average percentage of recordings with AF/AFL/AT among patients with detected AF/AFL/AT recurrence $56 \%$ vs $77 \%$, respectively; rate ratio [RR], 0.71; 95\% CI, 0.53-0.95; $P=.02$ ) (Table 1). The PVI and biatrial maze groups also had a lower proportion of TTM recordings exhibiting AF/AFL/AT than those undergoing MVS alone (PVI vs MVS alone: RR, 0.74; 95\% CI, 0.52-1.03; $P=.08$; biatrial maze vs MVS alone: RR, $0.66 ; 95 \%$ CI, 0.44-0.99; $P=.05$ ). However, the proportion of TTM recordings with AF/AFL/AT was similar between the 2 lesion-set groups (OR, 0.90; 95\% CI, 0.57-1.43; $P=.6$ ).

\section{Prevalence of AF/AFL/AT}

In both the MVS-alone and ablation procedure groups, estimated prevalence of AF/AFL/AT peaked within 2 weeks of surgery, declined for several months, then stabilized (Figure 2, $A$ and Figure E7, A). This pattern was evident in the raw frequency data that did not account for repeated measurements in a given patient. Estimated prevalence was lower in the ablation group at months 3 (34\% vs $67 \%), 6$ (31\% vs $59 \%), 9(30 \%$ vs $58 \%)$, and $12(29 \%$ vs $58 \%)$ compared with the MVS-alone group (Table 2 and Appendix E4). This prevalence pattern was also seen in the 2 lesion sets (Figure 2, $B$ and Figure E7, B), with an estimated prevalence of AF/AFL/AT in the PVI group that was higher than that in the biatrial maze group at months 3 ( $41 \%$ vs $28 \%$ ), 6 ( $37 \%$ vs $24 \%$ ), 9 (36\% vs $23 \%$ ), and $12(36 \%$ vs $23 \%)$ (Table 2 and Appendix E4), as was also apparent in the raw frequency data. 
TABLE 1. Effect of surgical ablation on prevalence of atrial fibrillation, flutter, or atrial tachycardia: Zero-inflated and negative binomial models

\begin{tabular}{llc}
\hline \multicolumn{1}{c}{ Model } & Result & $\boldsymbol{P}$ value \\
\hline $\begin{array}{l}\text { Analysis of surgical ablation vs no ablation } \\
\quad \text { Zero-inflated* }\end{array}$ & \\
$\quad$ Surgical ablation vs MVS & $4.04(1.89-8.64)$ & $<.001$ \\
$\quad$ alone & & \\
Negative binomial $\dagger$ & & \\
$\quad$ Surgical ablation vs MVS & $0.71(0.53-0.95)$ & .02 \\
$\quad$ alone & & \\
Analysis of type of surgical ablation and no ablation & \\
Zero-inflated* & & \\
$\quad$ PVI vs MVS alone & $2.64(1.07-6.51)$ & .04 \\
$\quad$ Biatrial vs MVS alone & $6.11(2.56-14.61)$ & $<.001$ \\
$\quad$ Biatrial vs PVI & $2.31(0.95-5.65)$ & .07 \\
Negative binomial $\dagger$ & & \\
$\quad$ PVI vs MVS alone & $0.74(0.52-1.03)$ & .08 \\
$\quad$ Biatrial vs MVS alone & $0.66(0.44-0.99)$ & .05 \\
$\quad$ Biatrial vs PVI & $0.90(0.57-1.43)$ & .7 \\
\hline
\end{tabular}

Values for the zero-inflated model are presented as odds ratio $(95 \%$ confidence interval), whereas values for the negative binomial model are presented as rate ratio ( $95 \%$ confidence interval). MVS, Mitral valve surgery with concomitant left atrial appendage closure alone; $P V I$, pulmonary vein isolation. *The zero-inflated model is a logistic regression that models the probability of freedom from atrial fibrillation/atrial flutter/atrial tachycardia. $\dagger$ The negative binomial model is a negative binomial regression that models the mean count of transtelephonic monitoring recordings that show atrial fibrillation/atrial flutter/atrial tachycardia. The model includes an offset for the (log) number of transtelephonic monitoring recordings submitted by each patient.

In the early peaking period of estimated AF/AFL/AT prevalence, surgical ablation by either lesion set was superior to no ablation, although PVI appeared less effective than a biatrial maze (Table 2). In the later plateau period, prevalence of AF/AFL/AT after PVI was lower than after no ablation $(P=.01)$ and the biatrial maze was superior to PVI $(P=.02)$ (Table 2$)$.

\section{DISCUSSION}

\section{Principal Findings}

Statistical modeling of weekly TTM recordings in MVS patients with persistent or long-standing persistent AF suggests that when compared to PVI, a biatrial maze procedure may be associated with greater freedom from $\mathrm{AF} / \mathrm{AFL} / \mathrm{AT}$ and a lower estimated prevalence of AF/AFL/AT during the first 12 months after surgery. However, there was no statistically significant difference between the 2 lesion sets with respect to freedom from AF/AFL/AT or AF/AFL/AT load.

\section{AF in MVS Patients}

$\mathrm{AF}$ is present in $30 \%$ to $50 \%$ of patients who present for MVS. ${ }^{14}$ Left untreated, the arrhythmia is associated with reduced long-term survival and increased risk of stroke. ${ }^{15}$ Randomized clinical trials have shown that surgical ablation at the time of MVS reduces the likelihood of AF persisting by $50 \%$ or more. ${ }^{16-30}$ In addition, observational studies suggest that restoration of sinus rhythm in these patients improves long-term survival and quality of life while reducing the risk of late stroke. ${ }^{31}$ For these reasons, multiple guidelines and expert consensus reports recommend the addition of surgical ablation to MVS in patients with coexisting $\mathrm{AF}^{32-34}$

The use of surgical ablation in such MVS patients varies widely. ${ }^{35}$ Many of these patients receive neither ablation nor management of their left atrial appendage during MVS surgery. Furthermore, when ablation is performed, choice of lesion set is variable. Results presented herein may inform that choice within the context of this statistical modeling of weekly TTM data.

\section{The CTSN Trial}

The CTSN trial of surgical ablation for AF during MVS randomized 260 patients with persistent or long-standing persistent AF requiring MVS to undergo either surgical ablation or no ablation. ${ }^{2}$ The largest randomized clinical trial in MVS patients with AF, the trial employed the 2012 Heart Rhythm Society definitions of persistent and long-standing persistent $\mathrm{AF}$ in place at the time of trial design. ${ }^{1,36}$ The majority of patients had long-standing persistent $\mathrm{AF}$ and would be classified as such according to the revised 2017 multisociety definitions.

The Food and Drug Administration-specified primary end point of the trial was freedom from $\mathrm{AF}$ or AF/AFL at both 6 and 12 months as assessed by 72-hour Holter monitoring. Patients who died before the 12-month assessment, were too ill to undergo heart-rhythm assessment, or underwent subsequent ablation therapy for $\mathrm{AF}$ were considered treatment failures. A greater proportion of patients in the ablation group than in the MVS-alone group were free of $\mathrm{AF}$ or $\mathrm{AF} / \mathrm{AFL}$ at both 6 and 12 months (63\% vs $29 \% ; P<.001)$, confirming the early-term effectiveness of surgical ablation for (long-standing) persistent $\mathrm{AF}^{2}$

Nested within this trial was a comparison of 2 lesion sets: PVI and biatrial maze. ${ }^{1}$ The trial was not powered to detect a difference between these lesion sets using the primary, Holter-monitor-based end point. In fact, analysis of Holter results revealed no apparent difference between the lesion sets. Analysis of weekly TTM recordings enabled an additional comparison of the 2 lesion sets and potential identification of differences in heart rhythm outcomes that might emerge if more events were identified with alternative rhythm monitoring. ${ }^{37,38}$

\section{Monitoring After Surgical Ablation}

Participants in the CTSN trial were given a TTM device and instructed to transmit weekly rhythm recordings and additional information when they experienced symptoms that might be attributable to a heart rhythm abnormality. 

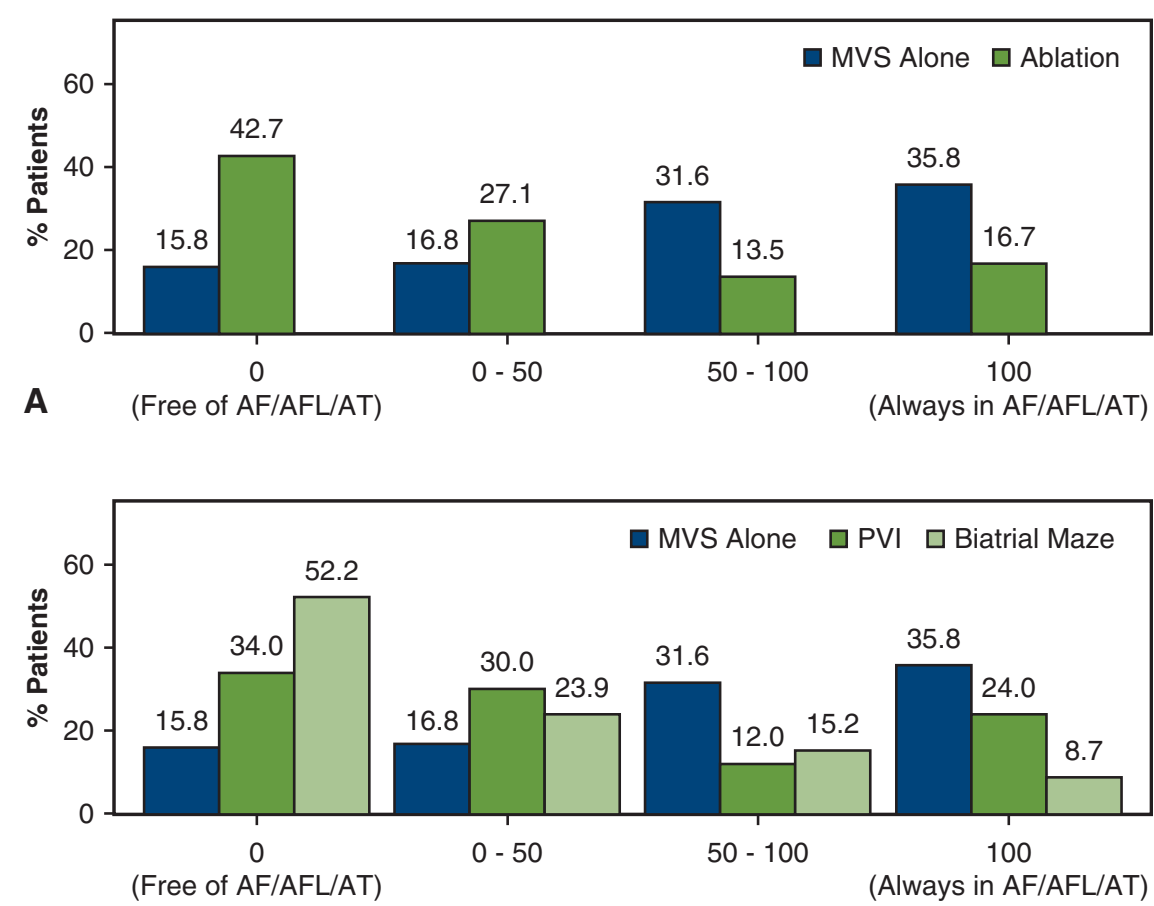

B

Percent of TTM Strips with AF/AFL/AT

FIGURE 1. Distribution of percent of transtelephonic monitoring $(T T M)$ recordings indicating atrial fibrillation, flutter, or atrial tachycardia (AF/AFL/AT) by randomization group. In each case the percent of patients free of AF/AFL/AT throughout the period 3 months through 12 months after surgery is indicated with a 0 , and those with AF/AFL/AT on all recordings are indicated by 100 . A, Comparison of those undergoing mitral valve surgery (MVS) alone and those with a concomitant ablation procedure. B, Comparison of those with MVS alone and those undergoing concomitant pulmonary vein isolation $(P V I)$ or a biatrial maze ablation procedure.

The NIH provided support to develop novel statistical methodology to analyze TTM data and apply this methodology to the data acquired from the trial. Need for this type of methodology was noted in a 2002 opinion piece ${ }^{8}$ and in the 2007 surgical ablation guidelines ${ }^{6}$ extant at the inception of the trial.

\section{Comparison of Analytical Methods}

The analyses presented in this article illustrate 2 approaches to a binary (AF/AFL/AT, yes-no) outcome assessed multiple times over the trial period. The first is simpler, consisting of counting TTM recordings showing AF/AFL/AT. Particularly in a randomized trial, with patients monitored over the same time span, and with adherence to TTM transmission frequency, its results are intuitive. The complex modeling of prevalence is less intuitive in that it is estimated continuously in time. Its advantage is that it accounts for actual time of each transmission, thereby using more of the information, is relatively insensitive to occasional dropouts, and in a real world setting accommodates data on patients monitored for unequal durations, unequal frequencies, and irregular intervals. $^{7-13}$ In this study, prevalence of AF/AFL/AT based on crude frequency counts across time closely mirrored the formal parametric estimates.

\section{Comparison of Monitoring Strategies}

Analysis of TTM data using the statistical methods reported herein confirmed that surgical ablation reduced the estimated prevalence of AF when compared with no ablation, and also suggested that by some estimates a biatrial maze procedure may be associated with less postoperative AF in the 12 months after surgery.

These results do not contradict the original report of the CTSN trial, which focused on 72-hour Holter monitor results at 6 and 12 months. ${ }^{1}$ The Holter recordings were used to determine prevalence of $\mathrm{AF}$ at these 2 discrete time points. In contrast, weekly rhythm on short rhythm strips by TTM provided brief snapshots of rhythm at frequent intervals. At the time the trial was designed, it was well established that more intensive monitoring detects more atrial arrhythmias, because much of the AF/AFL/AT is paroxysmal and may not be detected by assessing rhythm for a 72-hour period only at 6 and 12 months. ${ }^{37,38}$ Because effective sample size of a binary (yes-no) outcome is the number of events, we hypothesized that there would be added statistical power in frequent, though intermittent, monitoring. The application of this newly developed statistical methodology to analyze thousands of heart rhythm data-points obtained at given, but somewhat irregular, time points with occasional dropout created the 

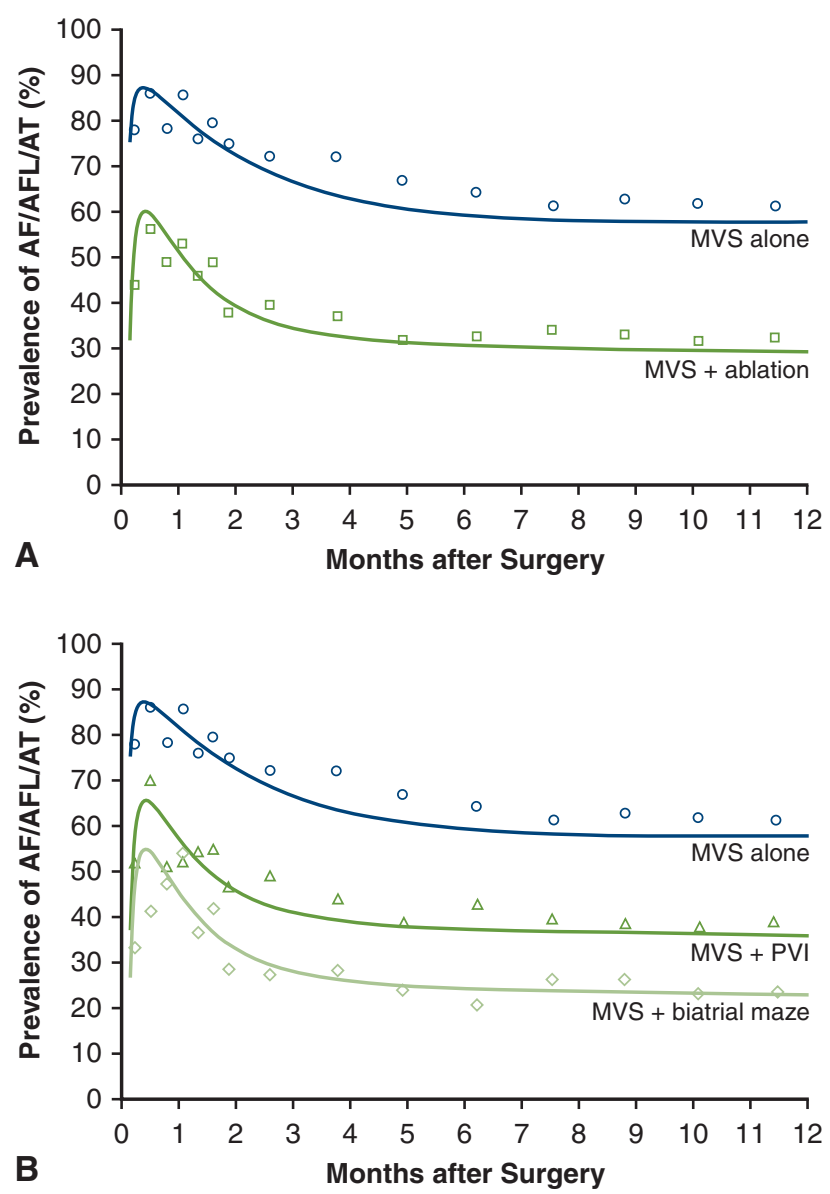

FIGURE 2. Estimated prevalence of atrial fibrillation, flutter, or atrial tachycardia (AF/AFL/AT), stratified by randomization to mitral valve surgery (MVS) alone or to a concomitant ablation procedure. Solid lines represent parametric estimates; symbols represent grouped raw frequency data without regard to repeated measurements as a crude verification of model fit. A, MVS alone versus MVS + an ablation procedure. B, MVS alone versus MVS + ablation via pulmonary vein isolation $(P V I)$ or biatrial maze.

opportunity, we hypothesized, to detect differences between ablation lesion sets with smaller sample size.

Although 2017 practice guidelines suggest that long-term monitoring at 1 year should be among the benchmarks for assessing success of AF ablation, there is no scientific certainty that this—or any — strategy represents the optimal means of judging the success of ablation. ${ }^{3}$ Implantable loop recorders and permanent pacemakers can detect asymptomatic AF (or high-rate atrial activity) in many patients who have undergone apparently successful ablation. However, it is not clear whether brief bursts of asymptomatic AF in such patients should be considered a treatment failure. In addition, loop recorders have limitations. By their nature, they overwrite data when memory is full, and they loop. Limited-memory devices may instead store daily AF/AFL/AT burden by cumulating number of hours each day the patient is in an atrial arrhythmia (Appendix E5). In this case, accuracy will depend on the algorithm used to detect the arrhythmia and its duration.

\section{Limitations}

Although the CTSN study of surgical ablation for AF during MVS is the largest randomized clinical trial examining heart rhythm outcomes in these patients, ${ }^{2}$ and application of both Holter monitoring and TTM to assess heart rhythm informs a discussion of monitoring strategies after ablation, ${ }^{1}$ this trial has several limitations. It was designed in 2010, and technology has advanced. Thus, specific ablation techniques were not uniform across the multiple Network centers, based on knowledge, methods of ablation, and energy sources available then compared with current recommendations. ${ }^{34}$ PVI was achieved by either two separate pulmonary-vein-encircling lesions or a box lesion in the posterior left atrium. In addition, energy sources varied and included cryothermy, unipolar radiofrequency, and bipolar radiofrequency. It is possible that these variations could have influenced results. $^{34}$

Specific limitations of the present study are that although 7949 TTM recordings were available for analysis, few patients submitted exactly the 50 weekly measurements specified by the protocol at the same time of day, and 32 patients had no rhythm data. Other studies confirm that compliance with electronic heart rhythm transmission schedules presents a challenge to patients ${ }^{3,37,39}$; given the large volume of data obtained, it is unlikely that additional recordings would have altered the results. No attempt was made to fill in these gaps. In the zero-inflated binomial model, an offset term was incorporated to adjust for variation in number of strips transmitted (number of opportunities for an AF/AFL/AT event to be detected). However, this does not directly address the problem of occasional missing TTM data, including transmitted, but uninterpretable, rhythm strips. For the parametric prevalence model, gaps were addressed as in any regression analysis that effectively interpolates a continuous estimate across time.

TTM was not conducted during the 6- and 12-month 72-hour Holter recordings; thus, we cannot compare TTM and Holter detection of atrial arrhythmias. We do not have data at each weekly interval on the use of antiarrhythmic medications, only snapshots of antiarrhythmic medications at 3, 6, 9, and 12 months after surgery, so cannot contrast rhythm on and off these medications. The well-established zero-inflated binomial model does not utilize the additional information provided by timing of the events. Information may be added by considering both zero-inflated values and 1-inflated values, representing both no AF/AFL/AT and persistent AF/AFL/ 
TABLE 2. Effect of surgical ablation on prevalence of atrial fibrillation, flutter, or atrial tachycardia: Longitudinal temporal decomposition model (Appendix E4)

\begin{tabular}{lcc}
\hline \multicolumn{1}{c}{ Factor } & $\begin{array}{c}\text { Estimate } \pm \text { standard } \\
\text { error }\end{array}$ & P value \\
\hline $\begin{array}{l}\text { Analysis of surgical ablation vs no ablation } \\
\text { Early peaking period } \\
\quad \text { Surgical ablation vs }\end{array}$ & $-2.2 \pm 0.30$ & $<.0001$ \\
$\quad$ MVS alone & & \\
Later plateau period & & \\
$\quad$ Surgical ablation vs & $-6.6 \pm 1.7$ & .0001 \\
$\quad$ MVS alone & & \\
Analysis of type of surgical ablation and no ablation & \\
Early peaking period & & .0002 \\
PVI vs MVS alone & $-1.5 \pm 0.39$ & $<.0001$ \\
Biatrial vs MVS alone & $-2.9 \pm 0.40$ & $<.0001$ \\
Biatrial vs PVI & $-1.9 \pm 0.40$ & \\
Later plateau period & & .01 \\
PVI vs MVS alone & $-5.4 \pm 2.2$ & .0007 \\
Biatrial vs MVS alone & $-7.5 \pm 2.2$ & .02 \\
Biatrial vs PVI & $-5.2 \pm 2.3$ & \\
\hline
\end{tabular}

$M V S$, Mitral valve surgery with concomitant left atrial appendage closure alone; $P V I$, pulmonary vein isolation.

AT. ${ }^{40}$ The model of prevalence takes into account the time of each rhythm recording and provides an overview-an ensemble average - of the prevalence of AF/AFL/AT existing in the group of patients, but does not predict whether a given patient will or will not be in AF/AFL/AT. At the present time, software for comprehensive analysis of longitudinal data remains incompletely developed.

\section{CONCLUSIONS}

The variability in the estimates of AF/AFL/AT recurrence after surgical ablation in the CTSN trial suggests the need to reassess current definitions of success, optimal methods for rhythm monitoring, and best practices for statistical analysis of such data. Intensity of atrial rhythm monitoring affects estimates of AF/AFL/AT occurrence, load, and prevalence-the more one assesses rhythm, the more arrhythmias one is likely to observe. ${ }^{37,38}$ This gives rise to inherent differences between twice-yearly Holter monitoring and weekly (plus symptom-driven) TTM assessments that underlie different interpretations of lesion set efficacy. Novel statistical approaches suggest that by some measures, a biatrial maze procedure may be more effective than PVI in reducing AF/AFL/AT during the 12 months after surgery, as is also suggested by raw frequency data across time. There is need for a confirmatory randomized clinical trial of these alternative lesion sets. In the meantime, work continues on this and additional new analytic approaches that may increase the efficiency of such a trial.

\section{Webcast}

You can watch a Webcast of this AATS meeting presentation by going to: https://aats.blob.core.windows.net/media/ 17AM/2017-05-02/BallroomABC/05-02-17_BallroomABC_ 1720_Gillinov.mp4.

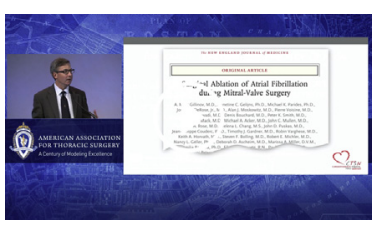

\section{Conflict of Interest Statement}

Dr Ailawadi reports being on consultant boards for Abbott, Edwards, Medtronic, and AtriCure. Dr Smith reports receiving grants from the National Institutes of Health/ CTSN; personal fees from Abbott Vascular, Edwards LifeSciences, and St Jude; and grants from Edwards LifeSciences. Dr Gillinov reports being a consultant to AtriCure, Medtronic, Abbott, CryoLife, Edwards LifeSciences, and ClearFlow. Cleveland Clinic has right to royalties from AtriCure. All other authors have nothing to disclose with regard to commercial support.

\section{References}

1. Gillinov AM, Argenziano M, Blackstone EH, Iribarne A, DeRose JJ Jr, Ailawadi G, et al. Designing comparative effectiveness trials of surgical ablation for atrial fibrillation: experience of the cardiothoracic surgical trials network. $J$ Thorac Cardiovasc Surg. 2011;142:257-64.e2.

2. Gillinov AM, Gelijns AC, Parides MK, DeRose JJ Jr, Moskowitz AJ, Voisine P, et al. Surgical ablation of atrial fibrillation during mitral-valve surgery. $N$ Engl J Med. 2015;372:1399-409.

3. Calkins H, Hindricks G, Cappato R, Kim YH, Saad EB, Aguinaga L, et al. 2017 HRS/EHRA/ECAS/APHRS/SOLAECE expert consensus statement on catheter and surgical ablation of atrial fibrillation. Heart Rhythm. 2017;14:e275-444.

4. Willems S, Khairy P, Andrade JG, Hoffmann BA, Levesque S, Verma A, et al. Redefining the blanking period after catheter ablation for paroxysmal atrial fibrillation: insights from the ADVICE (adenosine following pulmonary vein isolation to target dormant conduction elimination) trial. Circ Arrhythm Electrophysiol. 2016;9.

5. Reddy VY, Neuzil P, d'Avila A, Laragy M, Malchano ZJ, Kralovec S, et al. Balloon catheter ablation to treat paroxysmal atrial fibrillation: what is the level of pulmonary venous isolation? Heart Rhythm. 2008;5:353-60.

6. Shemin RJ, Cox JL, Gillinov AM, Blackstone EH, Bridges CR. Guidelines for reporting data and outcomes for the surgical treatment of atrial fibrillation. Ann Thorac Surg. 2007:83:1225-30.

7. Rajeswaran J, Blackstone EH, Ehrlinger J, Li L, Ishwaran H, Parides MK. Probability of atrial fibrillation after ablation: using a parametric nonlinear temporal decomposition mixed effects model. Stat Methods Med Res. 2018;27:126-41.

8. Gillinov AM, Blackstone EH, McCarthy PM. Atrial fibrillation: current surgical options and their assessment. Ann Thorac Surg. 2002;74:2210-7.

9. Gillinov AM, McCarthy PM, Blackstone EH, Pettersson G, Calhoun R, Sabik JF, et al. Bipolar radiofrequency to ablate atrial fibrillation in patients undergoing mitral valve surgery. Heart Surg Forum. 2004;7:E147-52.

10. Gillinov AM, McCarthy PM, Blackstone EH, Rajeswaran J, Pettersson G, Sabik JF, et al. Surgical ablation of atrial fibrillation with bipolar radiofrequency as the primary modality. J Thorac Cardiovasc Surg. 2005;129:1322-9.

11. Gillinov AM, Sirak J, Blackstone EH, McCarthy PM, Rajeswaran J, Pettersson G, et al. The Cox maze procedure in mitral valve disease: predictors of recurrent atrial fibrillation. J Thorac Cardiovasc Surg. 2005;130:1653-60.

12. Gillinov AM, Bakaeen F, McCarthy PM, Blackstone EH, Rajeswaran J, Pettersson G, et al. Surgery for paroxysmal atrial fibrillation in the setting of 
mitral valve disease: a role for pulmonary vein isolation? Ann Thorac Surg. 2006; 81:19-26; discussion 7-8.

13. Gillinov AM, Bhavani S, Blackstone EH, Rajeswaran J, Svensson LG, Navia JL, et al. Surgery for permanent atrial fibrillation: impact of patient factors and lesion set. Ann Thorac Surg. 2006;82:502-14.

14. Gillinov AM, Saltman AE. Ablation of atrial fibrillation with concomitant cardiac surgery. Semin Thorac Cardiovasc Surg. 2007;19:25-32.

15. Lee R, McCarthy PM, Wang EC, Vaduganathan M, Kruse J, Malaisrie SC, et al. Midterm survival in patients treated for atrial fibrillation: a propensity-matched comparison to patients without a history of atrial fibrillation. J Thorac Cardiovasc Surg. 2012;143:1341-51; discussion 50-1.

16. Khargi K, Deneke T, Haardt H, Lemke B, Grewe P, Muller KM, et al. Saline-irrigated, cooled-tip radiofrequency ablation is an effective technique to perform the maze procedure. Ann Thorac Surg. 2001;72:S1090-5.

17. Jessurun ER, van Hemel NM, Defauw JJ, Brutel De La Riviere A, Stofmeel MA, Kelder JC, et al. A randomized study of combining maze surgery for atrial fibrillation with mitral valve surgery. J Cardiovasc Surg (Torino). 2003;44:9-18.

18. Akpinar B, Guden M, Sagbas E, Sanisoglu I, Ozbek U, Caynak B, et al. Combined radiofrequency modified maze and mitral valve procedure through a port access approach: early and mid-term results. Eur J Cardiothorac Surg. 2003; 24:223-30

19. Schuetz A, Schulze CJ, Sarvanakis KK, Mair H, Plazer H, Kilger E, et al. Surgical treatment of permanent atrial fibrillation using microwave energy ablation: a prospective randomized clinical trial. Eur J Cardiothorac Surg. 2003;24:475-80; discussion 80.

20. Vasconcelos JT, Scanavacca MI, Sampaio RO, Grinberg M, Sosa EA, Oliveira SA. Surgical treatment of atrial fibrillation through isolation of the left atrial posterior wall in patients with chronic rheumatic mitral valve disease. A randomized study with control group. Arq Bras Cardiol. 2004;83:211-8. 03-10.

21. de Lima GG, Kalil RA, Leiria TL, Hatem DM, Kruse CL, Abrahao R, et al. Randomized study of surgery for patients with permanent atrial fibrillation as a result of mitral valve disease. Ann Thorac Surg. 2004;77:2089-94; discussion 94-5.

22. Doukas G, Samani NJ, Alexiou C, Oc M, Chin DT, Stafford PG, et al. Left atrial radiofrequency ablation during mitral valve surgery for continuous atrial fibrillation: a randomized controlled trial. JAMA. 2005;294:2323-9.

23. Abreu Filho CA, Lisboa LA, Dallan LA, Spina GS, Grinberg M, Scanavacca M, et al. Effectiveness of the maze procedure using cooled-tip radiofrequency ablation in patients with permanent atrial fibrillation and rheumatic mitral valve disease. Circulation. 2005;112:I20-5

24. Blomstrom-Lundqvist C, Johansson B, Berglin E, Nilsson L, Jensen SM, Thelin S, et al. A randomized double-blind study of epicardial left atrial cryoablation for permanent atrial fibrillation in patients undergoing mitral valve surgery: the SWEDish multicentre atrial fibrillation study (SWEDMAF). Eur Heart J. 2007;28:2902-8.

25. Albrecht A, Kalil RA, Schuch L, Abrahao R, Sant'Anna JR, de Lima G, et al. Randomized study of surgical isolation of the pulmonary veins for correction of permanent atrial fibrillation associated with mitral valve disease. $J$ Thorac Cardiovasc Surg. 2009;138:454-9.

26. von Oppell UO, Masani N, O'Callaghan P, Wheeler R, Dimitrakakis G, Schiffelers S. Mitral valve surgery plus concomitant atrial fibrillation ablation is superior to mitral valve surgery alone with an intensive rhythm control strategy. Eur J Cardiothorac Surg. 2009:35:641-50.

27. Budera P, Straka Z, Osmancik P, Vanek T, Jelinek S, Hlavicka J, et al. Comparison of cardiac surgery with left atrial surgical ablation vs. cardiac surgery without atrial ablation in patients with coronary and/or valvular heart disease plus atrial fibrillation: final results of the PRAGUE-12 randomized multicentre study. Eur Heart J. 2012;33:2644-52.

28. Damiano RJ Jr, Schwartz FH, Bailey MS, Maniar HS, Munfakh NA, Moon MR, et al. The Cox maze IV procedure: predictors of late recurrence. J Thorac Cardiovasc Surg. 2011;141:113-21.

29. Gillinov M, Soltesz E. Surgical treatment of atrial fibrillation: today's questions and answers. Semin Thorac Cardiovasc Surg. 2013;25:197-205.

30. Gillinov AM. Ablation of atrial fibrillation with mitral valve surgery. Curr Opin Cardiol. 2005;20:107-14.

31. Ad N, Cheng DC, Martin J, Berglin EE, Chang BC, Doukas G, et al. Surgical ablation for atrial fibrillation in cardiac surgery: a consensus statement of the International Society of Minimally Invasive Cardiothoracic Surgery (ISMICS) 2009. Innovations (Phila). 2010;5:74-83.

32. January CT, Wann LS, Alpert JS, Calkins H, Cigarroa JE, Cleveland JC Jr, et al. 2014 AHA/ACC/HRS guideline for the management of patients with atrial fibrillation: executive summary: a report of the American College of Cardiology/American Heart Association task force on practice guidelines and the Heart Rhythm Society. Circulation. 2014;130:2071-104.

33. Badhwar V, Rankin JS, Damiano RJ Jr, Gillinov AM, Bakaeen FG, Edgerton JR, et al. The Society of Thoracic Surgeons 2017 clinical practice guidelines for the surgical treatment of atrial fibrillation. Ann Thorac Surg. 2017;103:329-41.

34. Ad N, Damiano RJ Jr, Badhwar V, Calkins H, La Meir M, Nitta T, et al. Expert consensus guidelines: examining surgical ablation for atrial fibrillation. J Thorac Cardiovasc Surg. 2017;153:1330-13354.e1.

35. Ad N, Suri RM, Gammie JS, Sheng S, O’Brien SM, Henry L. Surgical ablation of atrial fibrillation trends and outcomes in North America. J Thorac Cardiovasc Surg. 2012;144:1051-60.

36. Calkins H, Kuck KH, Cappato R, Brugada J, Camm AJ, Chen SA, et al. 2012 HRS/ EHRA/ECAS expert consensus statement on catheter and surgical ablation of atrial fibrillation: recommendations for patient selection, procedural techniques, patient management and follow-up, definitions, endpoints, and research trial design: a report of the Heart Rhythm Society (HRS) task force on catheter and surgical ablation of atrial fibrillation. Developed in partnership with the European Heart Rhythm Association (EHRA), a registered branch of the European Society of Cardiology (ESC) and the European Cardiac Arrhythmia Society (ECAS); and in collaboration with the American College of Cardiology (ACC), American Heart Association (AHA), the Asia Pacific Heart Rhythm Society (APHRS), and the Society of Thoracic Surgeons (STS). Endorsed by the governing bodies of the American College of Cardiology Foundation, the American Heart Association, the European Cardiac Arrhythmia Society, the European Heart Rhythm Association, the Society of Thoracic Surgeons, the Asia Pacific Heart Rhythm Society, and the Heart Rhythm Society. Heart Rhythm. 2012;9:632-96.e21.

37. Charitos EI, Stierle U, Ziegler PD, Baldewig M, Robinson DR, Sievers HH, et al A comprehensive evaluation of rhythm monitoring strategies for the detection of atrial fibrillation recurrence: insights from 647 continuously monitored patients and implications for monitoring after therapeutic interventions. Circulation 2012;126:806-14.

38. Hanke T, Charitos EI, Stierle U, Karluss A, Kraatz E, Graf B, et al. Twenty-four hour Holter monitor follow-up does not provide accurate heart rhythm status after surgical atrial fibrillation ablation therapy: up to 12 months experience with a novel permanently implantable heart rhythm monitor device. Circulation. 2009; 120:S177-84.

39. Gosciniak P, Kowalik I, Sielicki P, Brykczynski M. Predictors of short- and midterm recurrence of atrial fibrillation after surgical radiofrequency ablation: a sixmonth transtelephonic electrocardiogram monitoring study. Cardiol J. 2013;20: 499-505.

40. Li L, Mao H, Ishwaran H, Rajeswaran J, Ehrlinger J, Blackstone EH. Estimating the prevalence of atrial fibrillation from a three-class mixture model for repeated diagnoses. Biomed J. 2017;59:331-43.

Key Words: ablation, atrial arrhythmia, Cardiothoracic Surgical Trials Network, postablation heart rhythm monitoring, transtelephonic monitoring

\section{Discussion}

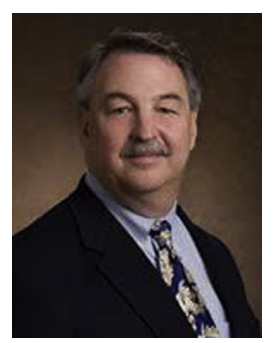

Dr James Edgerton (Dallas, Tex). Dr Gillinov, congratulations to you and your co-investigators on an eloquent study. Dr Gillinov and I have been friends for more than 15 years. I hold the utmost respect for him as an innovative researcher of high integrity. It is from that base of mutual respect that I am going to ask him 2 very pointed questions.

Dr Gillinov, your fourth slide indicates that your index publication was designed to compare 2 different lesion sets, but the supplementary materials that accompany the 
publication online did not list the comparison of pulmonary vein isolation and biatrial maze as either a primary or a secondary outcome of the study. In fact, in the Discussion you specifically state that the study was inadequately powered to compare different ablation sets. Furthermore, $20 \%$ of patients had missing data points that were imputed. I understand that no new patient data were added to the set before the subsequent analysis of transtelephonic monitoring, and that $12 \%$ of your patients failed to submit even 1 transtelephonic strip. So my question is, how can the conclusions in this follow-up study be any more valid than the conclusions in the index work when both were drawn from a data set that was inadequately powered to support them?

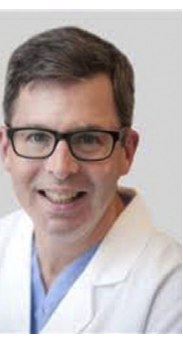

Dr A. Marc Gillinov (Cleveland, Ohio). The index study asked a slightly different question from this study, so let me explain. The index study asked the question, Does ablation provide better rhythm control than no ablation? So the ablation groups were grouped together as a single group-ablationand that study was well powered to compare ablation to no ablation and found ablation gives better rhythm control.

The study I presented today does include the same patients who had the procedures indicated, but it includes a large volume of new data-7949 new rhythm assessments. So, this study has new data and new methods of rhythm assessment that resulted in new insights into the procedure and lesion sets because we had far more power with this much data to compare lesion sets. We didn't know if it would be enough power, but it turns out, based on these analyses, we do get some preliminary answers about the effectiveness of the lesion sets.

Dr Edgerton. Thank you. The fundamental problem, of course, is that we have yet to determine a clinical definition of what constitutes success and must discuss success in terms of whatever monitoring modality is available or in vogue at that particular time. The modality with which I have the least experience is intermittent transtelephonic monitoring. Your work with sophisticated statistical analysis helps define the information obtainable from transtelephonic monitoring. But my question goes beyond that and involves whether this modality can ever have a clinical application. You and I both have seen published studies claiming success by remote telephonic monitoring, yet when we closely examine the data in those studies, $100 \%$ of patients at 1 time or another are experiencing atrial fibrillation. So although authors often claim success by transtelephonic monitoring, there are no patients who are free from atrial fibrillation.

You have chosen to study prevalence rather than incidence of atrial fibrillation in this particular work, but when a physician faces an individual patient in his or her office, the first branch point in decision making is usually binary: my patient has atrial fibrillation or my patient does not have atrial fibrillation. So tell me, is there a clinical application we can derive to help guide clinicians? It is okay if there isn't a clinical application, because your article has made other significant contributions to understanding what can be obtained from transtelephonic monitoring.

Dr Gillinov. Let's focus on what this means to you and me- the surgeons - and to our patients. Based on my interpretation of these data, I favor biatrial maze for patients who have mitral valve disease and atrial fibrillation, but the evidence base is not definitive. So I think it's going to help me to do the right operation. As to the question of how we should monitor patients after surgical ablation, for example, implant a loop recorder or have the patient come back for Holter monitors at 6 months and 12 months, that part I cannot answer because, as you point out, the more we look for atrial fibrillation, the more we are likely to find it. If a patient has had 31 seconds of atrial fibrillation over the course of a year, what is his risk? Does he need warfarin or an antiarrhythmic medication? Or should we simply ignore this brief bout of atrial fibrillation? Those questions remain unanswered at this point.

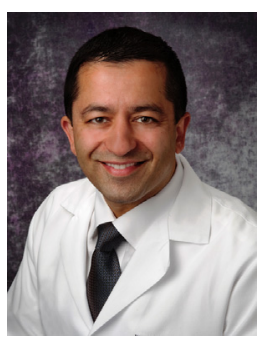

Dr Vinay Badhwar (Morgantown, $W V a)$. Before we ask Dr Damiano for a comment, would it be safe to say that this study is not truly answering the age-old question of the modality of measurement to discuss burden, but just making a statement about lesion set?

Dr Gillinov. Yes, I think it does make a statement about lesion set based on clinical inference and it reminds us, as Jimmy just said, that how often you look and the way you look provide different answers to questions concerning success of surgical ablation.

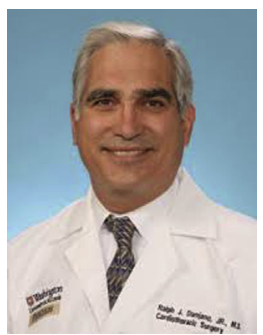

Dr Ralph Damiano (St Louis, Mo). Marc, congratulations on a great study. Jim, I thought those were fantastic questions. Dr Lee and I did a prospective study of whether continuous monitoring with a Reveal added anything to just intermittent Holter monitoring as recommended in the guidelines. The answer was absolutely not, and I think it depends on your success rate of whatever procedure you are doing. We did not look at pulmonary vein isolation or other potentially less successful procedures.

But I would first remind everyone that there is an end point for what success is after an ablation procedure, and Dr Edgerton has been part of the guidelines each time. And from the last set of published guidelines, the definition of success is freedom from all atrial tachyarrhythmias at 12 
months and off antiarrhythmic drugs, and any recurrence is defined as any atrial fibrillation lasting more than $30 \mathrm{sec}-$ onds. Now, we can disagree with that and I don't think it's great, but that's what has been decided. If we are responsible in how we report results, we have to report results consistent with what has been universally accepted. That's the definition. In your first article you didn't report it that way, but in the reanalysis, if you did look at success off drugs and any atrial fibrillation lasting longer than $30 \mathrm{sec}-$ onds, would you have reached the same conclusion because the way you were looking at it really hasn't been accepted as an appropriate method, and it's very hard to compare with previously published literature.

Dr Gillinov. We did not reanalyze it according to the Heart Rhythm Society's agreed-upon definitions. But I think the point here is that we should not just say, all right, that's the way it's going to be forever; let's accept those definitions. We need to keep studying how we analyze rhythm, and over time we will come up with definitions that are more useful.

Dr Damiano. I agree. Although just in terms of publishing stuff, that's what we have and we have to keep consistent, because if I decide what my success is and you decide independently a totally different criterion, we will never be able to compare.
Dr Gillinov. I certainly agree with that. Our initial end point for the bigger study was based on Food and Drug Administration requirements-there was no room for negotiation.

Dr Damiano. I would love in this article at least to include that in there just to see how it would compare to your other methods. To develop a new method you have to compare it to the accepted method that has been accepted by every single electrophysiologist and surgical society around the world.

The final thing is, if all the lesion sets were perfectly performed, this would be a good comparison. But as I remember from your original work, about $40 \%$ of the lesions were done with unipolar radio frequency, which has been abandoned for inefficacy. Is it really even a fair comparison? It would be a good comparison if you really were doing a pulmonary vein isolation exactly the same way and comparing it to a biatrial maze procedure. I wonder if you could just comment on the effect of ablation technology on your results.

Dr Gillinov. You're right, it would be better if we all did it exactly the same way so that we would have consistency in the literature, but this trial—conducted in a broad group of cardiac surgery centers-offers greater generalizability. 


\section{APPENDIX E1. CARDIOTHORACIC SURGICAL TRIALS NETWORK (CTSN) INVESTIGATORS INVOLVED IN THIS STUDY}

The members of the CTSN involved in this study include the National Heart, Lung, and Blood Institute (Marissa A. Miller, Wendy C. Taddei-Peters, Dennis Buxton, Amy Connolly, Nancy L. Geller, David Gordon, Neal O. Jeffries, and Albert Lee); the National Institute of Neurological Disorders and Stroke (Claudia S. Moy); and the Canadian Institutes of Health Research (Ilana Kogan Gombos, and Jennifer Ralph). The network chairs include Toronto General Hospital (Richard Weisel [chair]); Christiana Care Health System (Timothy J. Gardner [chair-emeritus]); Brigham and Women's Hospital (Patrick T. O'Gara [co-chair]); and Mount Sinai Health System (Eric A. Rose [vice chair]). Data Coordinating Centers include International Center for Health Outcomes and Innovation Research at Icahn School of Medicine at Mount Sinai (Annetine C. Gelijns, Michael K. Parides, Deborah D. Ascheim, Alan J. Moskowitz, Emilia Bagiella, Ellen Moquete, Helena Chang, Melissa Chase, Seth Goldfarb, Lopa Gupta, Katherine Kirkwood, Edlira Kumbarce, Ron Levitan, Karen O'Sullivan, Jessica Overbey, Milerva Santos, Michael Weglinski, Paula Williams, Carrie Wood, and Xia Ye).

Clinical site investigators include Baylor Research Institute (Michael Mack [PI], Tracine Adame, Natalie Settele, Jenny Adams, William Ryan, Robert L. Smith, and Paul Grayburn); Brigham and Women's Hospital (Frederick Y. Chen [PI], Anju Nohria, Lawrence Cohn, Prem Shekar, Sary Aranki, Gregory Couper, Michael Davidson, R. Morton Bolman III, Anne Burgess, and Debra Conboy); Christiana Care Health System (Ray Blackwell [PI], Roger Kerzner, Michael Banbury, and Andrea M. Squire); Cleveland Clinic (A. Marc Gillinov [PI], Eugene H. Blackstone, Bruce Lytle, Tomislav Mihaljevic, Pamela Lackner, Leoma Berroteran, Diana Dolney, Suzanne Fleming, Roberta Palumbo, Christine Whitman, Kathy Sankovic, and Denise Kosty Sweeney). National Heart, Lung, and Blood Institute Clinical Research Scholar is Gregory Pattakos. Columbia University (Michael Argenziano [PI], Mathew Williams, Lyn Goldsmith, Craig R. Smith, Yoshifumi Naka, Allan Stewart, Allan Schwartz, Daniel Bell, Danielle Van Patten, and Sowmya Sreekanth); Duke University (Peter K. Smith [PI], John H. Alexander, Carmelo A. Milano, Donald D. Glower, Joseph P. Mathew, J. Kevin Harrison, and Stacey Welsh); East Carolina Heart Institute (T. Bruce Ferguson [PI], Alan P. Kypson, Evelio Rodriguez, Malissa Harris, Brenda Akers, and Allison O'Neal); Emory University (John D. Puskas [PI], Vinod H. Thourani, Robert Guyton, Jefferson Baer, Kim Baio, and Alexis A. Neill); Hôpital Laval (Pierre Voisine [PI], Mario Senechal, François Dagenais, Kim O'Connor, Gladys Dussault, Tatiana Ballivian, and Suzanne Keilani); Montefiore-Einstein Heart Center (Robert E. Michler [PI], David A. D'Alessandro, Joseph
J. DeRose Jr, Daniel J. Goldstein, Ricardo Bello, William Jakobleff, Mario Garcia, Cynthia Taub, Daniel Spevack, Roger Swayze, and Nadia Sookraj); Montreal Heart Institute (Louis P. Perrault [PI], Arsène-Joseph Basmadjian, Denis Bouchard, Michel Carrier, Raymond Cartier, Michel Pellerin, Jean François Tanguay, Ismael El-Hamamsy, André Denault, Jonathan Lacharité, and Sophie Robichaud); Mount Sinai Medical Center (David H. Adams [PI], Robin Varghese, and Yael Mandel-Portnoy); NIH Heart Center at Suburban Hospital (Keith A. Horvath [PI], Philip C. Corcoran, Michael P. Siegenthaler, Mandy Murphy, Margaret Iraola, and Ann Greenberg); Ohio State University Medical Center (Chittoor Sai-Sudhakar [PI], Ayseha Hasan, Asia McDavid, and Bradley Kinn); University of Alberta Hospital (John C. Mullen [PI], Jonathan Choy, Steven Meyer, and Emily Kuurstra); University of Maryland (James S. Gammie [PI], Christopher R. DeFilippi, Dino T. Gaetani, Cindi A. Young, Dana Beach, and Julia Collins); University of Michigan (Steven F. Bolling [PI], Francis D. Pagani, and Cathie Bloem); University of Pennsylvania (Michael A. Acker [PI], Y. Joseph Woo, Mary Lou Mayer, Joseph E. Bavaria, Wilson Y. Szeto, Kenneth Margulies, Martin Keane, Helene Glassberg, Dinesh Jagasia, and James Kirkpatrick); University of Virginia Health System (Irving L. Kron [PI], Gorav Ailawadi, Karen Johnston, John M. Dent, John Kern, Jessica Keim, Sandra Burks, and Kim Gahring); and Yale New Haven Hospital (Abeel Mangi [PI], Joseph Akar, David Yuh, and Lynn Wilson).

Protocol Review Committee: David A. Bull (chair), Patrice Desvigne-Nickens (executive secretary), Dennis O. Dixon, Mark Haigney, Richard Holubkov, Alice Jacobs, Frank Miller, John M. Murkin, John Spertus, and Andrew S. Wechsler.

Data and Safety Monitoring Board: Frank Sellke (chair), Cheryl L. McDonald (executive secretary), Robert Byington, Neal Dickert, Dennis O. Dixon, John S. Ikonomidis, David O. Williams, Clyde W. Yancy, and John M. Canty Jr.

Medical Monitors: James C. Fang, Nadia Giannetti, and Wayne Richenbacher.

Overall Event Adjudication Committee: Vivek Rao (chair), Karen L. Furie, Rachel Miller, Sean Pinney, William C. Roberts, and Mary N. Walsh.

Echo Core Lab: Massachusetts General Hospital (Judy Hung and Xin Zeng).

Electrophysiology Core Lab: University of Rochester Medical Center (Jean-Philippe Couderc).

TTM Core Lab: Medicomp, Inc (Dan Balda, Wayne Bowen, Mauri Wilson, and Anne Schering).

\section{APPENDIX E2. PROTOCOL-PRESCRIBED LESION SETS FOR SURGICAL ABLATION FOR ATRIAL FIBRILLATION ${ }^{\mathrm{E} 1}$}

We provide the following narrative of lesion sets from the trial protocol to describe the state of the art in 2010 when the 
trial of surgical ablation for (long-standing) persistent atrial fibrillation was designed.

\section{Pulmonary Vein Isolation Alone or With Biatrial Maze Lesion Set Using Bipolar Energy Source}

Bipolar energy sources are preferred for pulmonary vein isolation (PVI) alone and for the PVI component of the biatrial maze lesion set. For patients randomized to PVI alone, 2 separate encircling lesions will be made around the left and right pulmonary veins (Figure E1, A). For patients randomized to the biatrial maze lesion set, the left atrial lesions will include the 2 encircling lesions as well as connecting lesions to the pulmonary veins, from the pulmonary veins to the mitral valve anulus, and from the pulmonary veins to the left atrial appendage (LAA) (Figure E1, B). The right pulmonary veins will be isolated first. Isolation will be confirmed by pacing the pulmonary veins at the previously identified threshold for capture. If no atrial capture is noted, it will be inferred that the right pulmonary veins were isolated. If atrial capture is noted, additional ablations on the atrial cuff will be performed until isolation is confirmed. This protocol will be repeated on the left pulmonary veins.

\section{Pulmonary Vein Isolation Alone or With Biatrial Maze Lesion Set Using Unipolar Energy Source}

PVI should be achieved with a bipolar ablation device. However, if patient anatomy, a minimally invasive approach, or surgeon preference dictates use of a unipolar device, such device may be employed to create a box lesion to encircle the pulmonary veins and other connecting lesions (Figure E1, C). If the patient is randomized to the PVI-alone or biatrial maze lesion set and a unipolar energy source is employed to create an epicardial box lesion, ablation will be performed on the arrested heart from the endocardial aspect. A box lesion will be created around all 4 pulmonary veins on the arrested heart from the endocardial aspect. The connecting lesions from the pulmonary veins to the mitral valve anulus, and from the pulmonary veins to the LAA will be made next. It is recommended that the Estech Cooled Cobra device (AtriCure, Mason, Ohio) be used for this lesion, as its conformation ensures that this larger lesion can be made linearly and contiguously. If a unipolar energy source is used as noted above, the surgeon will attempt to confirm conduction block at the pulmonary vein level after reperfusing the heart but before separation from bypass. If the surgical approach is minimally invasive via the right chest, the pacing protocol will be followed for the right pulmonary veins. If the surgical approach is sternotomy, the pacing protocol will be followed for the right pulmonary veins and then for the left pulmonary veins. In confirming conduction block, pacing from the pulmonary veins will be attempted at a rate $20 \mathrm{bpm}$ greater than the intrinsic heart rate at outputs of 5, 10, 15, and 20 MA.

\section{Remaining Lesions}

After PVI, the heart will be arrested and LAA excised or excluded. The remainder of the procedure for patients randomized to the biatrial maze lesion set will be performed at a point in the operation dictated by the surgeon's standard practice. Components of this biatrial maze lesion set will include:

- Left atriotomy: The left atrium will be opened adjacent to the interatrial groove, anterior to the right pulmonary veins.

- Connecting lesions from right to left pulmonary veins: This applies to patients in whom a bipolar energy source was used for PVI. A bipolar device will be used to create separate lesions between superior pulmonary veins and between inferior pulmonary veins.

- Connecting lesion to mitral anulus: A cryosurgical device or unipolar heat-based device will be used to create a connection from the box lesion to the mitral anulus. This lesion will be directed toward the P3 segment of the mitral valve.

- Connecting lesion to left atrial appendage: After excising or excluding the appendage, a unipolar or bipolar energy source will be used to create a connecting lesion from its orifice to the box lesion.

- Right atrial lesions: A vertical right atriotomy will be made beginning from the atrioventricular groove and extending toward the fossa ovalis. A unipolar energy source will be used to connect this lesion to the tricuspid anulus at the $2 \mathrm{o}$ 'clock position as viewed by the surgeon (part A of Figure E1, D). A unipolar or bipolar energy source will be used to connect the posterior aspect of this atriotomy to the superior and inferior vena cavae (part B of Figure E1, D). An incision will be created in the body of the right atrial appendage and a unipolar energy source used to connect the incision to the tricuspid anulus at the 10 o'clock position as viewed by the surgeon (part C of Figure E1,D). At the discretion of the surgeon, patients with a history of atrial flutter are candidates for the right atrial isthmus lesion.

\section{APPENDIX E3. ADHERENCE TO \\ TRANSTELEPHONIC MONITORING (TTM)}

Patients in the biatrial maze group submitted fewer TTM rhythm strips (median, 29) than patients in either the mitral valve surgery (MVS) alone group (median, 44) or pulmonary vein isolation (PVI) group (median, 45); however, 61 out of 66 patients $(92 \%)$ in the biatrial maze group submitted at least 1 strip, as did 108 out of 127 patients $(85 \%)$ in the MVS-alone group and 59 out of 67 patients $(88 \%)$ in the PVI group. Further, only $64 \%$ of patients (39 out of 61 ) in the biatrial group transmitted strips for at least 10 months, 
compared with $80 \%$ of patients ( 86 out of 108 ) in the MVSalone group and $78 \%$ of patients (46 out of 59 ) in the PVI group.

A concern is that patients submitting more TTM recordings may have done so in response to being in atrial fibrillation, flutter, or atrial tachycardia (AF/AFL/AT). If this were true, the proportion of TTM strips indicating AF/ AFL/AT would be an increasing fraction of the total number of TTMs transmitted. Figure E3, $B$, does not support this.

\section{APPENDIX E4. TEMPORAL DECOMPOSITION MODEL FOR POSTOPERATIVE ATRIAL RHYTHM BASED ON TRANSTELEPHONIC MONITORING Model 1: Analysis of Surgical Ablation Versus No Ablation}

patient's AF/AFL/AT profile (Figures E6 and E7) yields mean time spent in AF/AFL/AT-AF/AFL/AT burden. We limited the estimates of time spent in AF/AFL/AT to 12 months, the duration of monitoring, and this is known as "restricted mean survival time (RMST)." ${ }^{2}$,E3 In this case, RMST is time spent in AF/AFL/AT. Integration was performed using the trapezoid rule and 1000 estimates across 12 months per patient. Median value of mean time in AF/AFL/AT at 12 months was calculated and compared using the Wilcoxon rank-sum test.

Patients in the mitral valve surgery (MVS) alone group were estimated to be in AF/AFL/AT a median of 9.7 months (15th and 85th percentiles, 1.3 months and 12 months, respectively) of the 12 months after surgery, compared with 1.6 months (15th and 85th percentiles, 0.3 months

$$
\frac{\widehat{\pi}_{i j}}{1-\widehat{\pi}_{i j}}=\exp \left[3.2+f(\beta ; X)+u_{i}\right] \frac{1.5}{\exp \left[\left(1.4 t_{i j}\right)^{-1.1}\right]\left(1.4 t_{i j}\right)^{2.1}}+\exp \left[f(\beta ; X)+5.1 u_{i}\right] \frac{0.68}{\left\{\exp \left[\left(0.26 t_{i j}\right)^{-2.6}\right]-1\right\}\left(0.26 t_{i j}\right)^{3.6}}
$$

where $\widehat{\pi}_{i j}$ is estimated probability of atrial arrhythmia end point at time $t_{i j}$ and $u_{i}$ is the patient-specific random effect. $f(\beta ; X)$ is a linear vector of variables $(\boldsymbol{X})$ modulating the prevalence of the arrhythmia, each weighted by corresponding coefficients $(\boldsymbol{\beta})$ in Table 2, top.

\section{Model 2: Analysis of Type of Surgical Ablation and No Ablation}

$$
\frac{\widehat{\pi}_{i j}}{1-\widehat{\pi}_{i j}}=\exp \left[3.2+f(\beta ; X)+u_{i}\right] \frac{1.5}{\exp \left[\left(1.4 t_{i j}\right)^{-1.1}\right]\left(1.4 t_{i j}\right)^{2.1}}+\exp \left[f(\beta ; X)+5.0 u_{i}\right] \frac{0.60}{\left\{\exp \left[\left(0.24 t_{i j}\right)^{-2.5}\right]-1\right\}\left(0.24 t_{i j}\right)^{3.5}}
$$

Where $\widehat{\pi}_{i j}$ is estimated probability of atrial arrhythmia end point at time $t_{i j}$ and $u_{i}$ is the patient-specific random effect. $f(\beta ; X)$ is a linear vector of variables $(X)$ modulating the prevalence of the arrhythmia, each weighted by corresponding coefficients $(\boldsymbol{\beta})$ in Table 2 , bottom.

\section{APPENDIX E5. TWELVE-MONTH ATRIAL FIBRILLATION/ATRIAL FLUTTER/ATRIAL TACHYCARDIA (AF/AFL/AT) BURDEN}

Just as the area beneath a survival curve depicts mean survival across time, integrating the area beneath each and 12 months, respectively) for the ablation group $(P<.0001)$. Within the ablation group, those receiving pulmonary vein isolation (PVI) were estimated to be in $\mathrm{AF} /$ AFL/AT 2.0 months (15th and 85th percentiles, 0.34 and 12 months, respectively) of the 12 months, and in the biatrial maze group 1.2 months (15th and 85th percentiles, 0.19 months and 9.5 months, respectively). $P$ value for difference between PVI and biatrial maze $=.05$ (see Figure E8).

\section{E-References}

E1. Surgical ablation versus no surgical ablation for patients with persistent or longstanding persistent atrial fibrillation undergiong mitral valve surgery. Available at: http://www.nejm.org/doi/suppl/10.1056/NEJMoa1500528/suppl_file/nejmoa1 500528_protocol.pdf. Accessed July 31, 2018.

E2. Pak K, Uno H, Kim DH, Tian L, Kane RC, Takeuchi M, et al. Interpretability of cancer clinical trial results using restricted mean survival time as an alternative to the hazard ratio. JAMA Oncol. 2017;3:1692-6.

E3. Huang B, Kuan PF. Comparison of the restricted mean survival time with the hazard ratio in superiority trials with a time-to-event end point. Pharm Stat. 2018;17:202-13.
} 

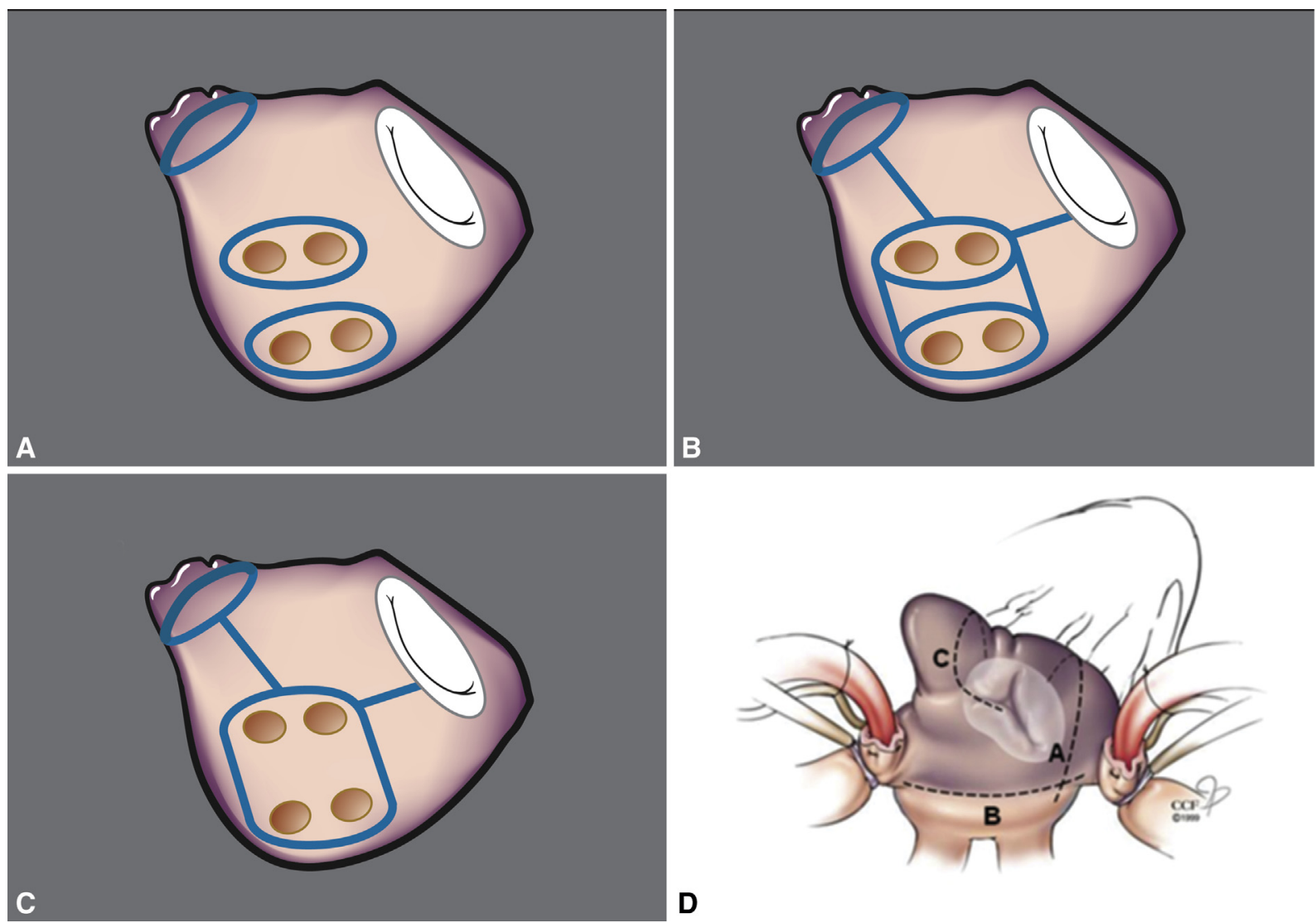

FIGURE E1. Illustration of ablation lesion sets. A, Interior of left atrium showing pulmonary vein isolation with a bipolar device. B, Interior of left atrium showing left atrial component of a biatrial lesion set with a bipolar device; connecting lesions to mitral valve are created with cryothermy. C, Interior of left atrium showing box lesion around pulmonary veins with connecting lesions to mitral valve and left atrial appendage. D, Right atrial lesion set. 


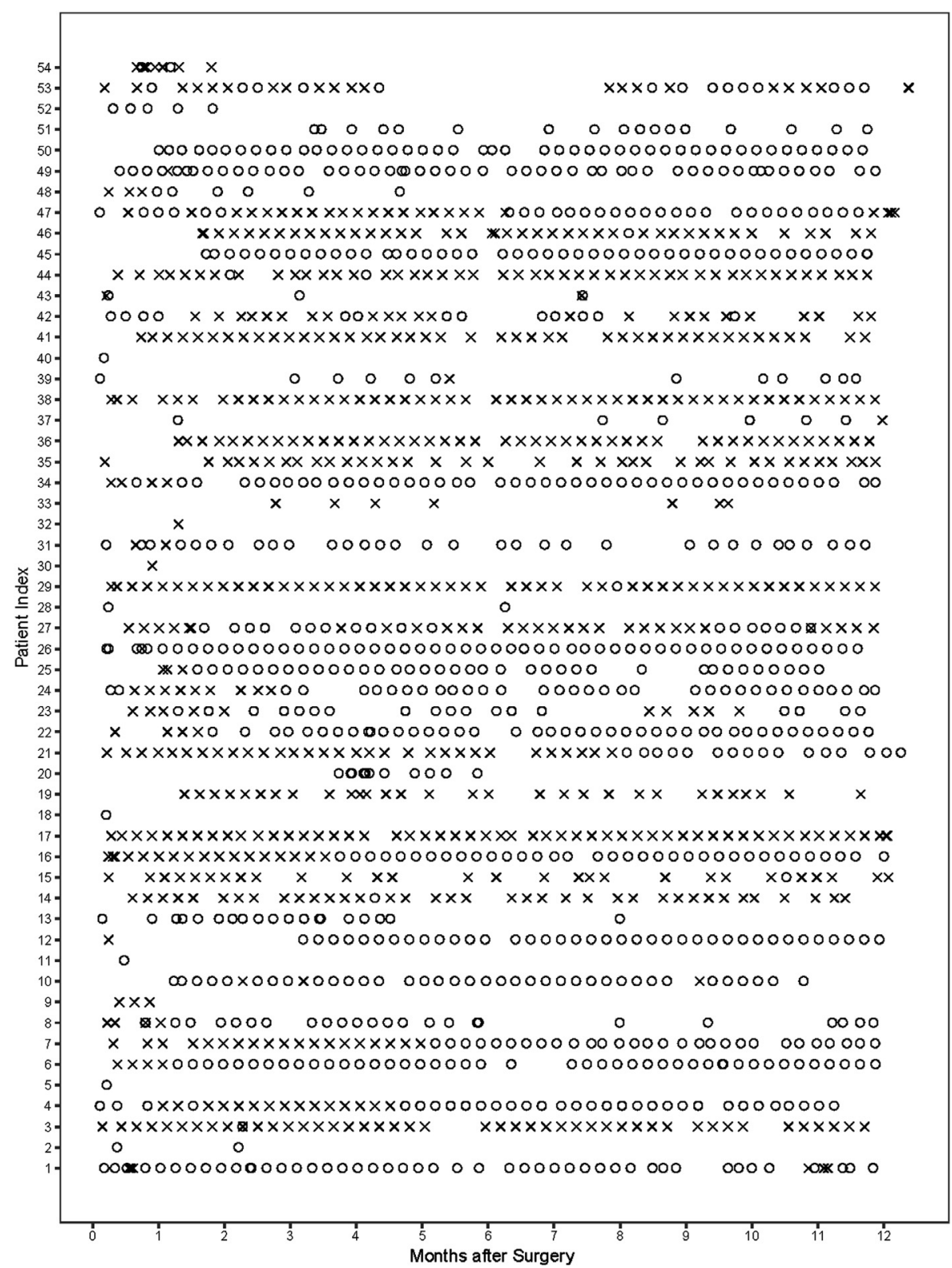

FIGURE E2. Individual rhythm profiles of 54 randomly selected patients ordered by date of telephonic rhythm transmission. Each symbol is a transmission: $\times$ denotes atrial fibrillation, flutter, or atrial tachycardia, and o denotes regular sinus rhythm. Gaps denote lack of weekly transmissions. Gaps clustered at 6 and 12 months represent weeks when 72-hour Holter monitoring occurred, during which patients were instructed not to transmit their rhythm. Other gaps were in part due to uninterpretable rhythm data. 


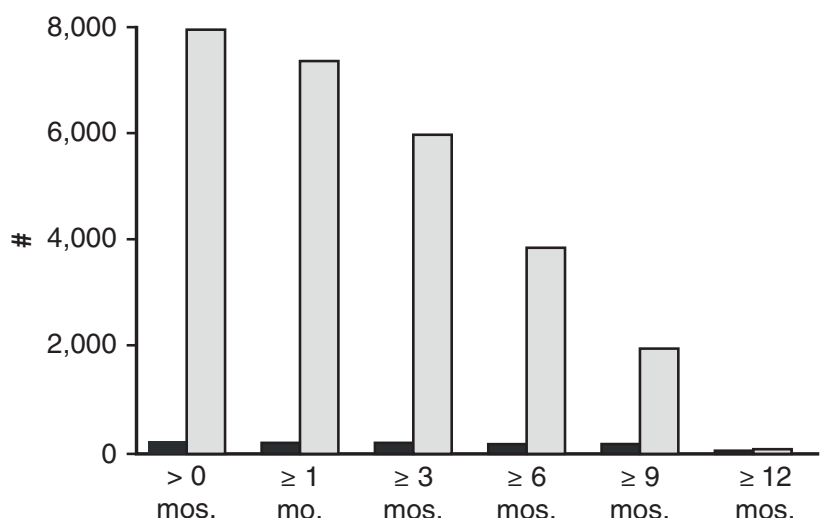

Time

Number of Patients 228 口 Number of TTMs 7949

202 190

5966

\begin{abstract}
176
\end{abstract}
3865

173

1964

37

87

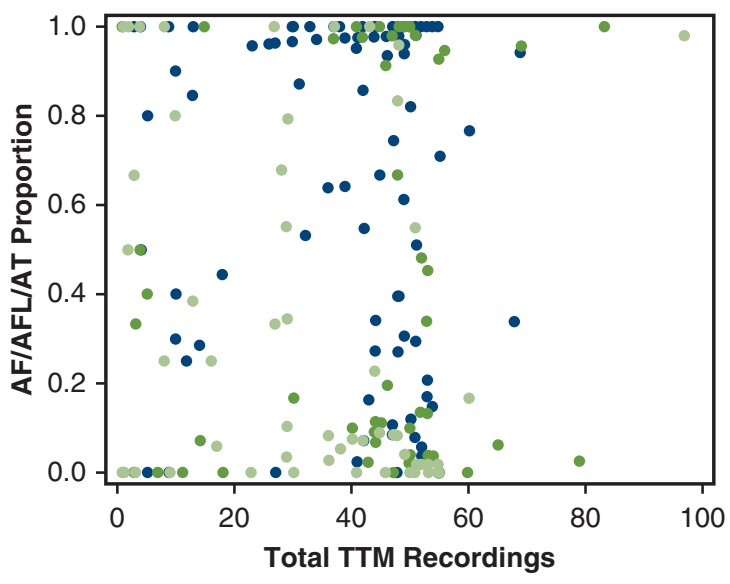

Group

- MVS Alone - MVS + PVI - MVS + Biatrial Maze

FIGURE E3. Transtelephonic (TTM) data collection over time. A total of 7949 TTM recordings were evaluated in 228 patients. A, Graph shows gradual attrition of patients transmitting over time, and the number of recordings available at and beyond designated time-points. Note that patients were instructed not to transmit rhythm simultaneous with 72-hour Holter monitoring at the 12-month point. Thus these few patients represent transmissions just at or beyond the 12-month point. B, Proportion of TTM recordings showing atrial fibrillation, flutter, or atrial tachycardia as a function of the total number of TTMs transmitted after mitral valve surgery alone versus with a concomitant biatrial maze or pulmonary vein isolation ablation procedure. One patient in the mitral valve surgery-alone group submitted more than $150 \mathrm{TTM}$ recordings and was excluded from the plot. Expected maximum number is 50. AF/AFL/AT, Atrial fibrillation, flutter, or atrial tachycardia; TTM, transtelephonic monitoring; MVS, mitral valve surgery; PVI, pulmonary vein isolation.

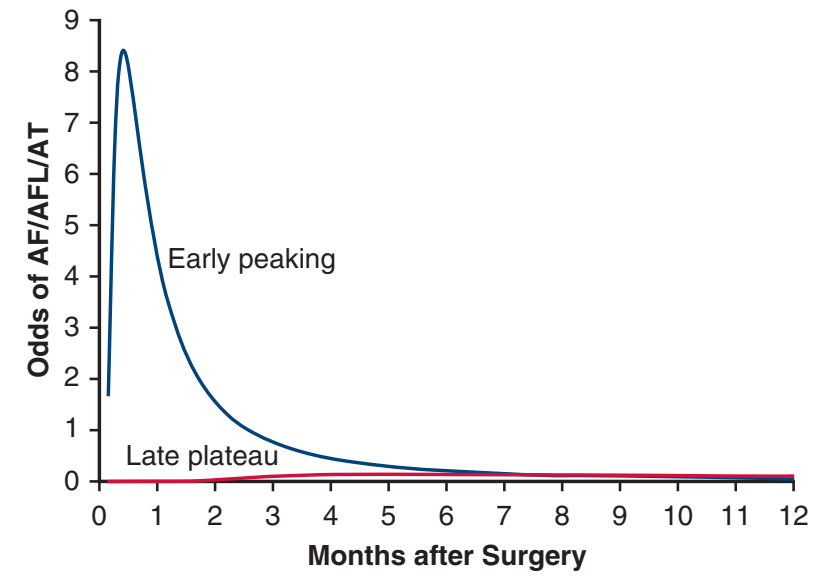

FIGURE E4. Temporal decomposition of odds of atrial fibrillation, flutter, or atrial tachycardia $(A F / A F L / A T)$ in the overall group for a typical patient (random effect $\mathrm{u}_{\mathrm{i}}=0$ ).

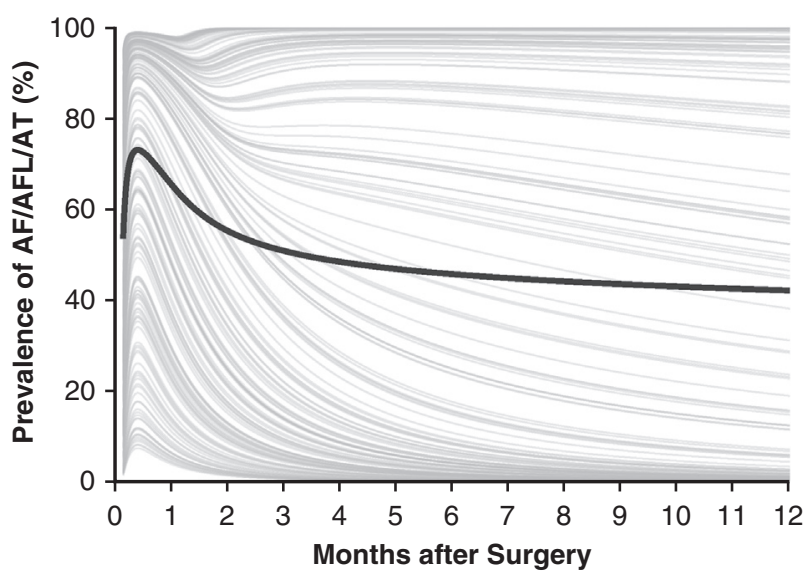

FIGURE E5. Estimated patient-specific profiles of the prevalence of atrial fibrillation, flutter, or atrial tachycardia (AF/AFL/AT) and the average of the profiles (thick black line). 


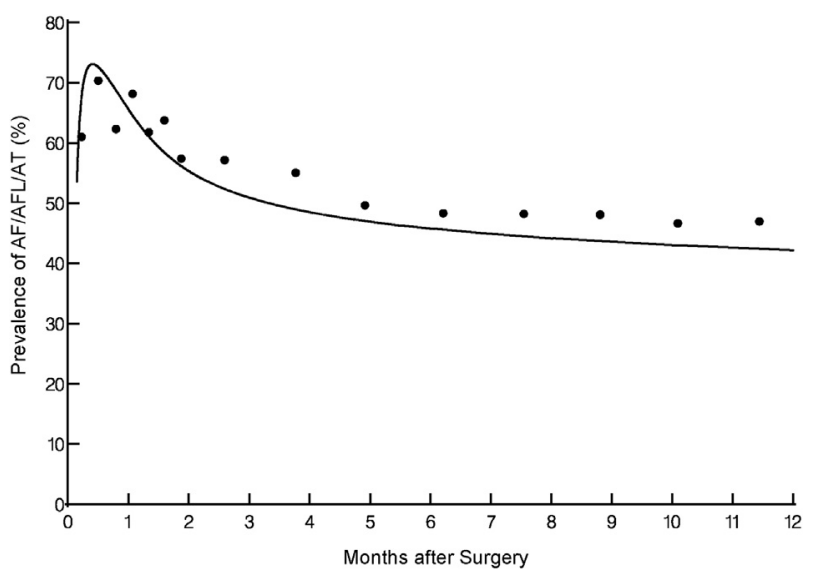

FIGURE E6. Temporal trend of prevalence of atrial fibrillation, flutter, or atrial tachycardia $(A F / A F L / A T)$ in the overall group. Solid line represents parametric estimates of percentage of patients in AF/AFL/AT at each moment after surgery. Circles represent data grouped (without regard to repeated measurements) within time frames to provide a crude verification of model fit.
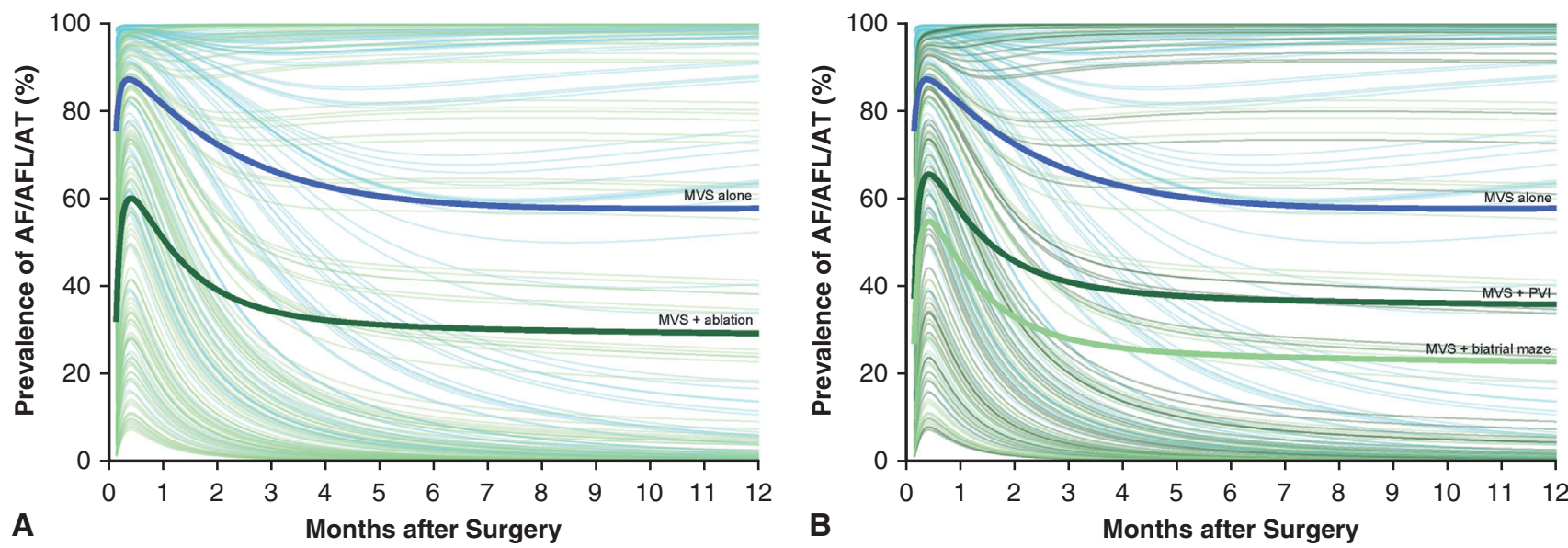

FIGURE E7. Individual patient profiles of prevalence of atrial fibrillation, flutter, or atrial tachycardia (AF/AFL/AT) across time, stratified by mitral valve surgery $(M V S)$ alone versus a concomitant ablation procedure. Thick lines are ensemble averages. A, MVS alone versus a concomitant ablation procedure. Blue lines depict MVS alone and green lines the concomitant ablation group. B, MVS alone (blue lines) versus pulmonary vein isolation (dark green lines) or biatrial maze (light green lines). PVI, Pulmonary vein isolation. 


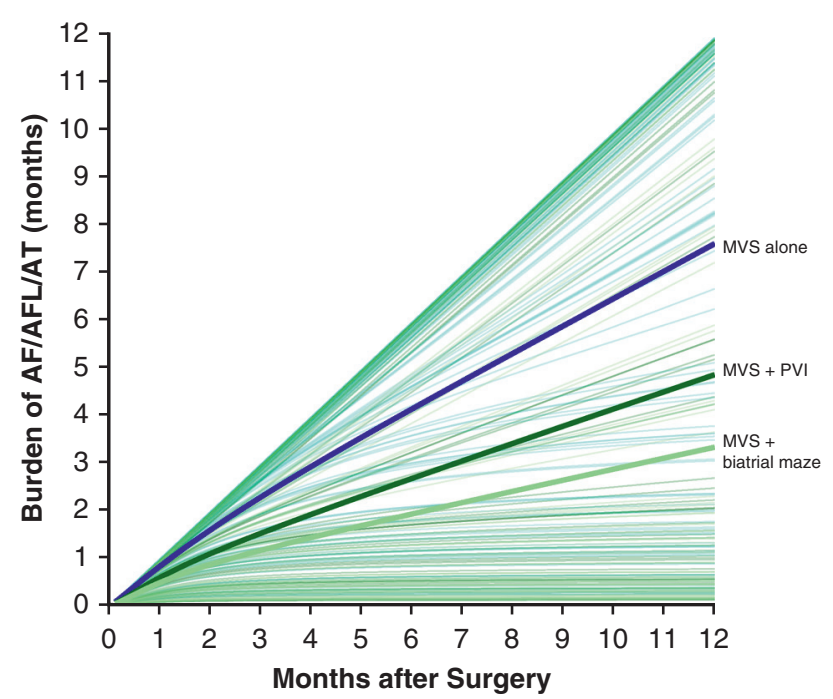

FIGURE E8. Individual patient profiles of cumulative atrial fibrillation, flutter, or atrial tachycardia (AF/AFL/AT) burden across time in months, stratified by mitral valve surgery $(M V S)$ alone versus ablation by pulmonary vein isolation $(P V I)$ or a biatrial maze procedure. A patient always in AF/AFL/AT will be depicted by a diagonal line from 0 to 12 months.

Thick lines are ensemble averages. 
TABLE E1. Patient characteristics and procedure details for treatment groups

\begin{tabular}{|c|c|c|c|}
\hline Characteristic & $\begin{array}{c}\text { Mitral valve } \\
\text { surgery alone } \\
\quad(\mathbf{n}=127) \\
\end{array}$ & $\begin{array}{c}\text { Mitral valve } \\
\text { surgery }+ \text { PVI } \\
(\mathrm{n}=67) \\
\end{array}$ & $\begin{array}{c}\text { Mitral valve surgery }+ \\
\text { biatrial maze } \\
(\mathbf{n}=66) \\
\end{array}$ \\
\hline Female & $63(50)$ & $29(43)$ & $28(42)$ \\
\hline Age (y) & $69 \pm 10$ & $71 \pm 10$ & $68 \pm 10$ \\
\hline White race & $112(88)$ & $55(82)$ & $61(92)$ \\
\hline Hispanic ethnic group & $8(6.3)$ & $3(4.5)$ & $7(11)$ \\
\hline Diabetes & $28(22)$ & $14(21)$ & $16(24)$ \\
\hline Renal insufficiency & $5(3.9)$ & $5(7.5)$ & $3(4.5)$ \\
\hline Previous CABG & $4(3.1)$ & $2(3.0)$ & $5(7.6)$ \\
\hline Previous PCI & $11(8.7)$ & $9(13)$ & $11(17)$ \\
\hline Cerebrovascular disease & $13(10)$ & $10(15)$ & $12(18)$ \\
\hline Use of anticoagulant & $97(76)$ & $55(82)$ & $50(76)$ \\
\hline Use of class III antiarrhythmic & $15(12)$ & $7(10)$ & $7(11)$ \\
\hline NYHA class III or IV & $62 / 126(49)$ & $31 / 67(46)$ & $25 / 66(38)$ \\
\hline \multicolumn{4}{|l|}{ Atrial fibrillation status } \\
\hline Longstanding persistent & $71(56)$ & $34(51)$ & $36(55)$ \\
\hline Persistent & $56(44)$ & $33(49)$ & $30(45)$ \\
\hline Occurrence of atrial fibrillation at least once daily* & $89 / 111(80)$ & $40 / 60(67)$ & $45 / 57(79)$ \\
\hline Short Form-12 physical-function score & $38 \pm 8.8$ & $38 \pm 8.5$ & $39 \pm 7.5$ \\
\hline \multicolumn{4}{|l|}{ Cause of mitral valve disease } \\
\hline Organic disease & $73(57)$ & $38(57)$ & $37(56)$ \\
\hline Functional nonischemic mitral regurgitation & $48(38)$ & $24(36)$ & $19(29)$ \\
\hline Ischemic mitral regurgitation & $6(4.7)$ & $5(7.5)$ & $10(15)$ \\
\hline Left ventricular ejection fraction $(\%)$ & $56 \pm 7.7$ & $56 \pm 8.0$ & $55 \pm 7.2$ \\
\hline Left atrial volume during early diastole $(\mathrm{mL})$ & $140 \pm 111$ & $124 \pm 66$ & $130 \pm 72$ \\
\hline \multicolumn{4}{|l|}{ Mitral valve surgery $\dagger$} \\
\hline Valve replacement & $61 / 126(48)$ & 25/67 (37) & $29 / 66(44)$ \\
\hline Valve repair & $65 / 126(52)$ & $42 / 67(63)$ & $37 / 66(56)$ \\
\hline Left atrial appendage management & $114 / 126(90)$ & $65 / 67(97)$ & $65 / 66(98)$ \\
\hline Suture closure & $43(38)$ & $21(32)$ & $27(42)$ \\
\hline Excised & $54(47)$ & $32(49)$ & $28(43)$ \\
\hline Clip closure & $17(15)$ & $12(18)$ & $10(15)$ \\
\hline \multicolumn{4}{|l|}{ Concomitant procedure $\dagger$} \\
\hline Surgical management of tricuspid regurgitation & $48 / 126(38)$ & 26/67 (39) & $24 / 66(36)$ \\
\hline Aortic valve replacement & $20 / 126(16)$ & $8 / 67(12)$ & $6 / 66(9.1)$ \\
\hline CABG & $25 / 126(20)$ & $8 / 67(12)$ & $19 / 66(29)$ \\
\hline Other & $11 / 126(8.7)$ & $10 / 67(15)$ & $6 / 66(9.1)$ \\
\hline CPB time $(\min ) \dagger$ & $132 \pm 51$ & $143 \pm 66$ & $152 \pm 61$ \\
\hline Aortic clamp time $(\min ) \ddagger$ & $96 \pm 36$ & $98 \pm 39$ & $107 \pm 44$ \\
\hline
\end{tabular}

Values are presented as $\mathrm{n}(\%)$ or mean \pm standard deviation. $P V I$, Pulmonary vein isolation; $C A B G$, coronary artery bypass grafting; $P C I$, percutaneous coronary intervention; $N Y H A$, New York Heart Association; $C P B$, cardiopulmonary bypass. *Atrial Fibrillation Severity Scale. †One patient withdrew consent before the index surgery. $\ddagger$ Thirteen patients did not have the aorta clamped and were excluded from calculations. One patient withdrew consent before the index surgery. 